\title{
Synergistic effects of cavitation erosion and corrosion for nickel aluminium bronze with oxide film in $3.5 \% \mathrm{NaCl}$ solution
}

\author{
J. Basumatary, R. J. K. Wood \\ National Centre of Advanced Tribology at Southampton, University of \\ Southampton, Highfield, S017 1BJ
}

\begin{abstract}
Cavitation erosion-corrosion of nickel aluminium bronze with oxide films formed under two different conditions, oxide formed in air for 1 week and oxide formed after 3 months immersion in $3.5 \% \mathrm{NaCl}$ solution, was conducted using a $19.5 \mathrm{kHz}$ indirect ultrasonic vibratory system at a peak-to-peak amplitude of $80( \pm 0.2) \mu \mathrm{m}$ in $3.5 \% \mathrm{NaCl}$ solution. The synergistic interactions between the cavitation erosion and corrosion were determined via experiment comprising of three different tests: pure cavitation erosion test in distilled water, pure in-situ electrochemical corrosion tests using open circuit potentials (OCP) and polarization scanning, and a combination of cavitation erosion-corrosion kept at OCP in 3.5\% $\mathrm{NaCl}$ solution to understand the overall synergism existing between cavitation wear and corrosion. The results were then analysed and compared using mass loss analysis. Scanning electron microscopy was used to analyse microstructural characteristics of the cavitated sample surfaces, as well as the transverse-sections of the surface features. It was seen that samples with water formed film exhibited high synergy and was more susceptible to selective phase attack and phase boundary erosion in comparison to air-formed film.
\end{abstract}

Keywords: cavitation erosion-corrosion; tribo-corrosion; synergy; nickel aluminium bronze

\section{Introduction}

Cavitation is a tribo-corrosion phenomenon known to occur within marine environment that may cause destruction of ships, boats and submarine propellers as well as rudders, greatly affecting their efficiency and reducing their life. Generally known to be a very complex process, it depends on the type and unsteadiness of the process along with the physical response of the propeller and rudder materials to the cavitation impact itself [1]. There have been many counter-measures to prevent or reduce further damage by cavitation. But due to ever increasing usage and sizes of bulk carriers and ocean liners, cavitation has become more prominent an issue. In a marine system, the marine propulsion system in general seems to be at a high risk of exposure to cavitation and its detrimental effects. Hence, a propeller material has certain properties that it must meet before it can be considered fit for boat and ship propeller fabrication. The properties required in a propeller material vary depending on the duty and service conditions of its vessel, however, certain factors are more commonly desirable for a propeller material to possess, such as high mechanical strength including ductility, fracture toughness and tensile strength, strength to weight ratio, high resistance to general corrosion, crevice corrosion and corrosion 
fatigue in seawater, high cavitation erosion resistance, high resistance to impingement attack, and ability to be repaired easily including weldability [2].

Understanding the material behaviour in different wear conditions as well as environments, and the synergistic interaction between the cavitation erosion and corrosion adds valuable insight into understanding the cavitation behaviour of the propeller materials.

As-cast nickel aluminium bronze (NAB), UNS C98500 (CuAl10Fe5Ni5), is a conventional marine propeller material alloy that has been studied in the literature to understand the role of its microstructure and material behaviour against cavitation erosion-corrosion. With the ability to retain its original smooth machined surface over a long period of time, and high notch resistance, as well as resistance to failure under impact when notched, it has become greatly valued as a marine propeller material [3]. As classed by Lloyd's Register, in the early 1960s the use of high-tensile brass accounted for about $64 \%$ of all of the propellers produced whereas, NAB accounted for only $19 \%$. However, by the mid 1980s NAB had acquired almost complete dominance over the other materials, accounting for about $82 \%$ of the propellers. This is attributed to a combination of high mechanical properties and superior corrosion resistance in seawater demonstrated by NAB over other engineering materials [2].

\subsection{Synergy}

Cavitation erosion-corrosion of NAB has since been studied most extensively to understand the behavioural response of NAB to cavitation, its microstructural characteristics, and more importantly the relation between cavitation erosion and corrosion of NAB. The tribo-corrosion process which involves mechanical as well as electrochemical interactions is known as synergism of wear and corrosion [4]. One way to determine this relationship is via performing a synergy experiment that involves three different types of test [5], [6]: (1) pure erosion tests to determine the erosive wear rate; (2) pure corrosion tests to determine the corrosive wear rate; (3) combined erosion and corrosion tests to determine the total wear rate. These experiments allow evaluation of the synergistic effect, by using Equation 1 conforming to ASTM G119 standards [7]:

$\mathrm{S}=\mathrm{T}-(\mathrm{E}+\mathrm{C})$ ... Eqn. 1

Where,

$\mathrm{S}$ is the synergistic wear rate,

E the erosive wear rate (test (1))

C the corrosive wear rate (test (2)), and

$\mathrm{T}$ the total wear rate (test (3)).

$\mathrm{S}, \mathrm{T}, \mathrm{E}$ and $\mathrm{C}$ can be either mass loss or depth-of-penetration rates.

S can also be represented using Equation 2:

$S=T-(E+C)=\Delta \mathrm{E}+\Delta \mathrm{C}$ 
Where, $\Delta \mathrm{E}=$ corrosion enhanced erosion, and

$\Delta \mathrm{C}=$ erosion enhanced corrosion.

The underlying mechanisms for $\Delta \mathrm{E}$ may generally include removal of workhardened surfaces due to corrosion, exposing the softer substrate to the erosion mechanisms; selective phase attack of grain boundaries; and an increase in the number of stress-concentrating defects (such as caused by corrosion micropitting). Whereas, $\Delta \mathrm{C}$ can occur due to local acidification occurring within the erosion pits, which may accelerate corrosion rates and prohibit further film formation; surface roughening due to erosion; or change in mechanical properties of the sample material, such as lowering of the fatigue strength, due to corrosion [8]. However, many attempts have been made in the past to understand and quantify the $\mathrm{S}$ into the separate $\Delta \mathrm{E}$ and $\Delta \mathrm{C}$ components. Attempts have been made to correlate them with microstructural analyses [9], or measure them using experimental (such as electrochemical) tests [10]-[12]. However, it has still proven difficult to be able to accurately quantify or separate the components from the $\mathrm{S}$ term.

A previous study was conducted to understand the synergy between cavitation erosion and corrosion of air-formed oxide filmed $\mathrm{NAB}$ in $3.5 \% \mathrm{NaCl}$ solution and distilled water [5]. Microstructural analysis was conducted for the eroded samples to understand the mechanisms involved. However, not much has been understood about the cavitation of NAB in the presence of a thick protective oxide layer that is known to form in the marine environment after only a few months of exposure. Furthermore, the impact it has on the synergistic interactions between the cavitation erosion and corrosion is also unknown. Hence, the aim and objective of the present study was to understand the impact of a water-formed oxide layer on the material behaviour during cavitation erosion-corrosion, and compare it with that of an air-formed filmed sample, along with the corrosion aspects of cavitation, the existence of synergism between erosion and corrosion, and the overall cavitation erosion-corrosion damage at room temperature in $3.5 \% \mathrm{NaCl}$ solution.

For this, the synergy experiment was conducted by means of an indirect ultrasonic vibratory system as presented in Ref [5]. The experiment conducted comprised of three different tests: pure cavitation erosion test in distilled water, pure corrosion tests using open circuit potentials (OCP) and polarization scanning in $3.5 \% \mathrm{NaCl}$ solution, and a combination of cavitation erosioncorrosion kept at OCP in 3.5\% $\mathrm{NaCl}$ solution. The results for $\mathrm{T}$ and $\mathrm{E}$ were then analysed and compared using gravimetric mass loss analysis.

\subsection{NAB microstructure and material behaviour}

NAB is a copper-based alloy (80 wt. \%) with aluminium as its main alloying element (10 wt. \%). In addition to that, it also constitutes 5 wt. \% of Fe and $\mathrm{Ni}$ each among other traces of elements. Together, these elements help NAB form its complex microstructure, which generally comprises of columnar grains of copper-rich solid solution known as $\alpha$-phase and a small volume fraction of $\beta$ phase or retained martensitic $\beta^{\prime}$-phase, surrounded by four different types of Fe- 
rich intermetallic kappa $(\kappa)$ phases. Among these intermetallic phases, $\kappa_{I}$ phase is rosette shaped precipitate ranging from $5-10 \mu \mathrm{m}$ in diameter. $\kappa_{I I}$ phase is smaller (ranging from 1-2 $\mu \mathrm{m}$ in diameter) dendritic rosette shaped phase distributed mostly at the $\alpha / \beta$ boundaries. $\kappa_{I I I}$ phase is a fine lamellar "finger-like" eutectoid structure. And $\kappa_{I V}$ phase is a fine precipitation with highest Fe-content among the intermetallics that is of varying sizes $(<0.5 \mu \mathrm{m}$ in diameter $)$ with plate-like morphology and is distributed throughout the $\alpha$-matrix [3], [5], [13]-[16] .

Figure 1 shows the general microstructural morphology of as-cast NAB tested in this paper under Scanning electron microscope (SEM) at 1000x magnification where, $\kappa_{I}$ and $\kappa_{I I}$ are the globular dendritic structures, $\kappa_{I I I}$ is the lamellar structure, and $\kappa_{I V}$ is the very fine particulate imbedded within the $\alpha$-matrix.

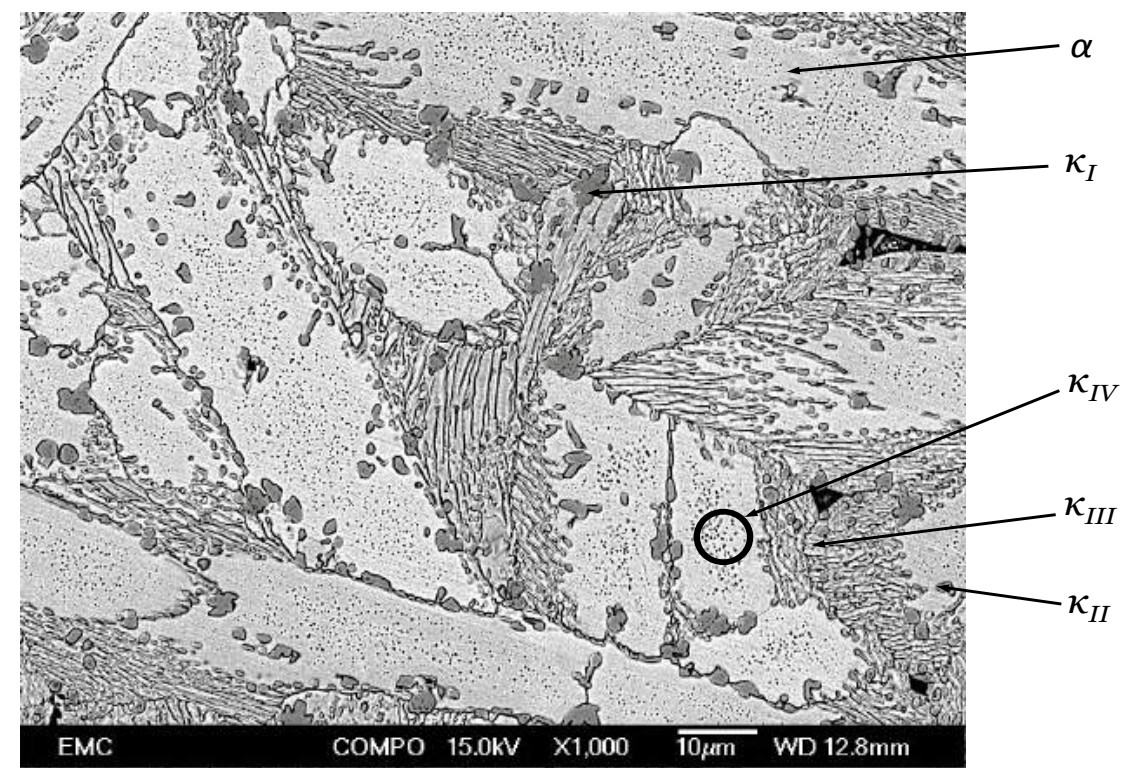

Fig. 1: SEM backscattered electron image of the microstructural morphology of cast NAB at a magnification of 1000x [17].

The $\kappa_{I}, \kappa_{I I}$ and $\kappa_{I V}$ phases are all distributed in the nickel-aluminium structure of $\mathrm{DO}_{3} \mathrm{Fe}_{3} \mathrm{Al}$ crystal structure. $\mathrm{DO}_{3}$ crystal structure is an ordered face centred cuboid (FCC) crystal unit cell with four body centred cubes (BCC) and four $\mathrm{Fe}_{3} \mathrm{Al}$ cubes arranged alternatively. $\kappa_{I I I}$ phase, on the other hand, is a Ni-rich $\mathrm{B}_{2}$ structure, which is a BCC unit with Ni elements at the eight corners but with $\mathrm{Al}$ element at the centre of the cube. Figure 2 illustrates the crystal structures of $\kappa_{l}$, $\kappa_{I I}$ and $\kappa_{I V}$ phases as $\mathrm{DO}_{3} \mathrm{Fe}_{3} \mathrm{Al}, \kappa_{I I I}$ phase as $\mathrm{B}_{2} \mathrm{NiAl}$ [16], [18]. 


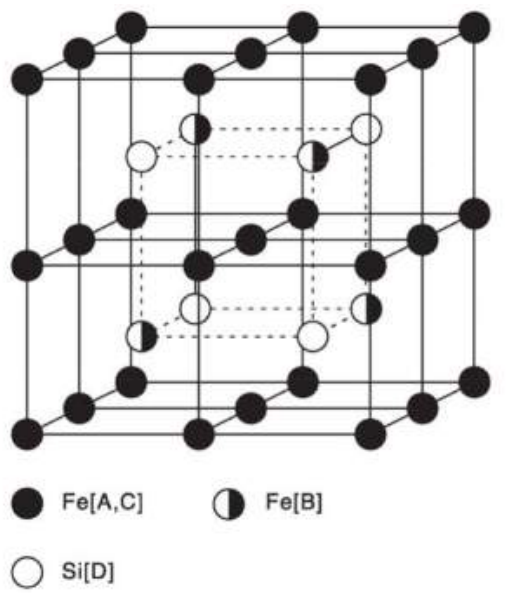

(a)

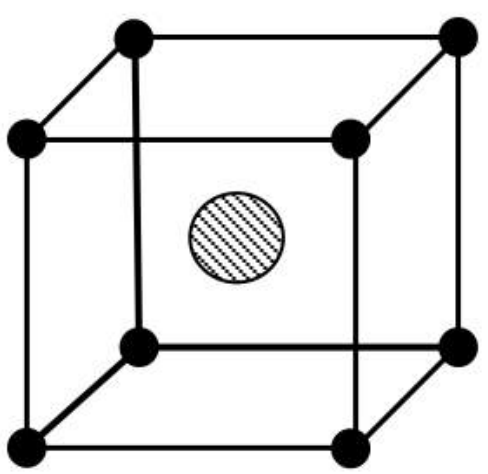

Ni

(b)

Fig. 2:(a) $\mathrm{Fe}_{3} \mathrm{Al} \mathrm{DO}_{3}$ structure, and (b) NiAl B2 structure [16], [18].

The chemical compositions, in weight \%, for the alloy as well as the individual phases obtained under energy-dispersive X-ray spectroscopy (EDS) are tabulated in Table 1.

\begin{tabular}{|c|c|c|c|c|c|c|c|c|}
\hline \multirow{2}{*}{$\begin{array}{c}\text { Micro- } \\
\text { structura } \\
\text { I Phases }\end{array}$} & \multicolumn{6}{|c|}{ Chemical composition in weight \% } & \multirow{2}{*}{ Morphology } & \multirow{2}{*}{ Structure } \\
\hline & $\mathrm{Cu}$ & $\mathbf{S i}$ & Al & Mn & $\mathbf{F e}$ & $\mathbf{N i}$ & & \\
\hline Alloy & 80.25 & 0.03 & 8.79 & 3.56 & 4.63 & 5.10 & - & - \\
\hline$\alpha$ & 85.39 & - & 7.19 & 0.87 & 3.35 & 3.20 & $\begin{array}{l}\text { FCC solid } \\
\text { solution }\end{array}$ & - \\
\hline$\kappa_{\mathrm{I}}$ & 15.08 & 1.66 & 13.29 & 1.72 & 57.53 & 10.72 & $\begin{array}{l}\text { Rosetta } \\
\text { globular }\end{array}$ & $\begin{array}{l}\mathrm{Fe}_{3} \mathrm{Al} \\
\left(\mathrm{DO}_{3}\right)\end{array}$ \\
\hline$\kappa_{\mathrm{II}}$ & 17.61 & 1.52 & 14.02 & 1.50 & 51.90 & 13.44 & Dendritic & $\begin{array}{l}\mathrm{Fe}_{3} \mathrm{Al} \\
\left(\mathrm{DO}_{3}\right)\end{array}$ \\
\hline$\kappa_{\text {III }}$ & 45.15 & - & 18.76 & 1.19 & 10.90 & 24.00 & Lamellar & $\begin{array}{l}\mathrm{NiAl} \\
\left(\mathrm{B}_{2}\right) \\
\end{array}$ \\
\hline$\kappa_{\mathrm{IV}}$ & 13.00 & 7.00 & 19.00 & 2.00 & 64.00 & 6.00 & Cuboidal & $\begin{array}{l}\mathrm{Fe}_{3} \mathrm{Al} \\
\left(\mathrm{DO}_{3}\right)\end{array}$ \\
\hline
\end{tabular}

Table 1: Chemical composition of the individual phases in the NAB samples as tested under EDS.

As-cast NAB used for the research had high mechanical properties with density of $7.65 \mathrm{~g} \mathrm{~cm}^{-3}$, ultimate tensile strength of $650 \mathrm{MPa}$, yield strength of $270 \mathrm{MPa}$, and hardness of $160 \mathrm{Hv}$.

The general corrosion rate of NAB in seawater is considered to be $0.06 \mathrm{~mm}$ year-1 [19], [20]. For the longevity of propellers functioning in a harsh environment like seawater, it is very important that the materials used for the propellers are highly corrosion resistant. One of the ways to determine the corrosion properties of a metal or alloy is by locating its position in the galvanic series to understand how it would fair in the seawater environment. The galvanic potentials of NAB in flowing salt water at a velocity of 2.5 to $4 \mathrm{~m} \mathrm{sec}^{-1}$ at a temperature range of $10-27^{\circ} \mathrm{C}$, is between -0.15 to $-0.22 \mathrm{~V}$ [21]-[23]. This good corrosion resistance of NAB has been attributed to the formation of a 
protective oxide layer predominantly comprising of aluminium oxide near the substrate and copper oxide formed on the outer layer, when exposed to a corrosive environment. These films generally take several weeks to reach a thickness of 900-1000 nm, which are not susceptible to localised breakdown and consequent pitting in the presence of chlorides and therefore, making NAB very resistant to corrosion by seawater, but may exhibit a different corrosion behaviour from the NAB substrate when disrupted via external means, such as cavitation [19], [24].

\subsection{Corrosion behaviour and selective phase attack}

In an alloy with multi-phase composition, the various phases tend to have different electrochemical potentials due to which, there exists a tendency for the most anodic phase to be corroded preferentially. This is called selective phase attack. The extent of corrosion depends on how great the potential difference is between the anodic phase and the surrounding phases, and upon the distribution and intrinsic corrosion resistance of the anodic phases [19].

In case of $\mathrm{NAB}$, the copper-rich $\alpha$-phase and aluminium-rich phases tend to undergo localised galvanic corrosion when coupled with the cathodic $\kappa$ phases, which tend to have higher electronegativity as compared to $\alpha$-phase. This selective phase attack affects especially the narrow bands of $\alpha$-phase adjacent to the lamellar $\kappa_{I I I}$ phases, from where it may spread further into the $\kappa_{I I I}$ phase itself [3], [5], [15], [25]-[30]. This vulnerability of $\alpha$ - $\kappa_{I I I}$ phase boundary is considered to be due to its continuous nature. This selective phase attack of the $\alpha-\kappa_{I I I}$ phase boundaries may reach up to a depth of $100 \mu \mathrm{m}$ in just a month of submersion in seawater [30]. A form of selective phase attack that arises in aluminium bronzes is commonly known as "dealuminification," where the aluminium in the alloy undergoes selective dissolution, resulting in a residue of spongy porous copper, which retains the original shape and dimensions of the component but has little mechanical strength. NAB has been known to suffer from dealuminification in acidic media both in service and in laboratory tests, and also, infrequently in marine environment [19], [31]. Generally the existence of the retained $\beta$-phase, especially in non-heat-treated $\mathrm{NAB}$, has a negative effect on dealuminification corrosion of aluminium bronzes, since it occurs first at the interface of the $\alpha$ matrix and the $\beta$-phase and then further develops within the $\beta$-phase [32], [33]. It has been found that controlling of the factors such as the composition of the alloy, and cooling rate from the working temperature of the cast, may ensure reduction in dealuminification of the alloy [19], [31].

\subsection{Oxide film formation processes}

There have been several studies on the corrosion behaviour of NAB alloy and its protective oxide film formation. Schüssler and Exner [34] established that when the oxide-free substrate surface is introduced to a corrosive environment, the aluminium in the alloy would preferentially oxidize first in the presence of oxygen. However, after a certain thickness is achieved, the formed alumina film, prevents further diffusion of aluminium, leaving copper to oxidize on the surface of the corrosion product [24], [34]. The formation of the $\mathrm{Al}_{2} \mathrm{O}_{3}$ oxide layer is done 
by "complexation" of aluminium by chloride as demonstrated in Equation 3, which is then followed by hydrolysis of the chloride product to form $\mathrm{Al}(\mathrm{OH})_{3}$ layer (Equation 4):

$\mathrm{Al}+4 \mathrm{Cl}^{-} \rightarrow \mathrm{AlCl}_{4}^{-}+3 \mathrm{e}^{-}$

...Eqn. 3

$\mathrm{AlCl}_{4}^{-}+3 \mathrm{H}_{2} \mathrm{O} \rightarrow \mathrm{Al}(\mathrm{OH})_{3}+3 \mathrm{H}^{+}+4 \mathrm{Cl}^{-}$

...Eqn. 4

The chloride ions released play an important role in the formation and properties of protective oxide films especially on copper-based alloys. Hence, it has been observed and established by Wharton and Stokes [30] that the most prominent oxide forming in aerated chloride media on a NAB surface is $\mathrm{Cu}_{2} \mathrm{O}$. This is because the main corrosion process in such environment mainly constitutes of the dissolution of copper to form a dichlorocuprous anion complex [30], [35], [36], given by Equation 5:

$\mathrm{Cu}+2 \mathrm{Cl}^{-} \rightarrow \mathrm{CuCl}_{2}^{-}+\mathrm{e}^{-}$ ...Eqn. 5

The $\mathrm{Cu}_{2} \mathrm{O}$ may form via a number of processes in $\mathrm{Cl}^{-}$containing environments, the extent of which depends on the relative chloride ion concentration and $\mathrm{pH}$. The oxide layers are considered are formed by a dissolution process shown in Equation 6 [37].

$2 \mathrm{CuCl}_{2}^{-}+2 \mathrm{OH}^{-} \rightarrow \mathrm{Cu}_{2} \mathrm{O}+\mathrm{H}_{2} \mathrm{O}+4 \mathrm{Cl}^{-}$ ...Eqn. 6

The predominant cathodic reaction in aerated solutions given by Equation 7:

$\mathrm{O}_{2}+2 \mathrm{H}_{2} \mathrm{O}+4 \mathrm{e}^{-} \rightarrow 4 \mathrm{OH}^{-}$ ...Eqn. 7

\section{Methodology}

\subsection{Sample preparation}

12 samples were prepared for the tests. Each sample had a dimension of $25 \times 25$ $\mathrm{mm}$ with a thickness of $5 \mathrm{~mm}$ with a tolerance of $\pm 2 \mathrm{~mm}$. The samples were all wired with the help of M3 screws at one side for facilitating electrochemical analyses. The sample surfaces were all coated with lacquer on 5 of the 6 sides of the sample, except one, the surface being monitored for oxide formation. 6 samples of NAB were wet polished with 120-, 800, 1200- and 4000- silicon carbide (SiC) abrasive papers and kept aside in 6 individual clean and uncontaminated plastic bags to form air-formed films for a maximum of 1 week.

The other 6 samples were wet polished with 120-, 800, 1200- and 4000- SiC grit paper and then submerged in $3.5 \% \mathrm{NaCl}$ solution for 3 months to form a thick layer of water-formed oxide film on the samples. Figure 3 shows the differences in the optical images of the oxide-films formed after 1 week of air exposure and 3 months of submersion in $3.5 \% \mathrm{NaCl}$ solution. 


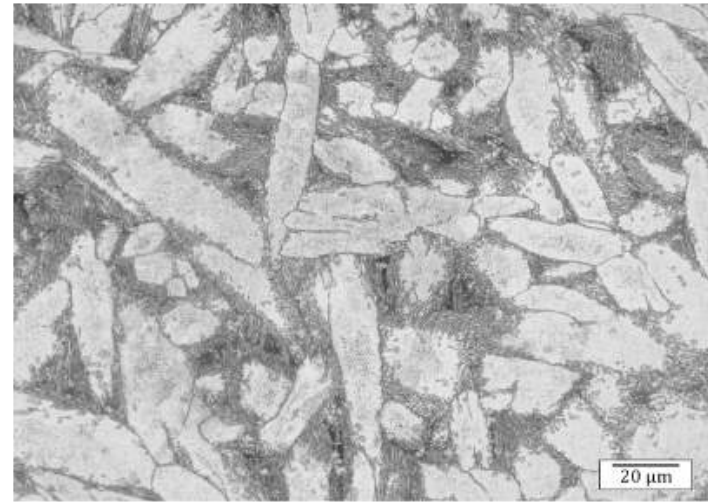

(a)

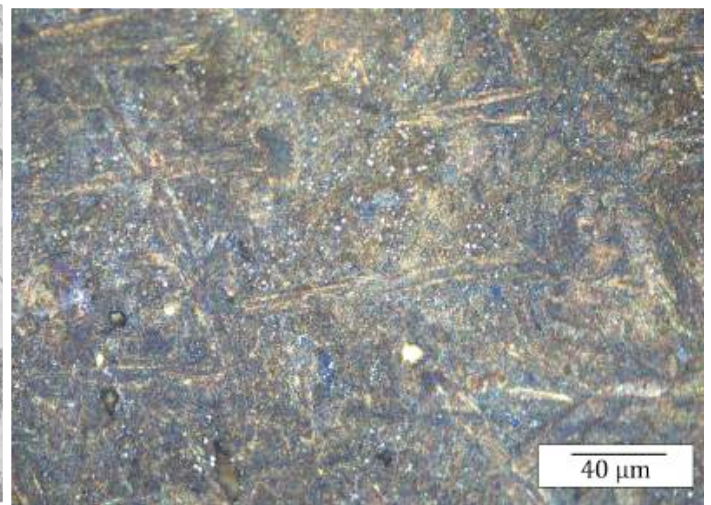

(b)

Fig. 3: 600x optical image of general oxide film (a) after 1 week in air; (b) after 3 months of immersion in 3.5\% NaCl solution.

From Figure 3 (a), it can be seen that considering the protective oxide film formation is a slow process, especially in the absence of corrosive environment like seawater, there is not a significance difference in the microstructure of the substrate after 1 week of exposure to air, although the $\kappa_{I I I}$ phases seemed to appear more prominent, meaning localised etching or selective phase attack at the phase boundaries. Whereas, in Figure 3 (b) the sample immersed for 3 months in 3.5\% $\mathrm{NaCl}$ solution had a completely different morphology where the microstructural details of the base material were no longer clearly visible.

\subsection{Protective oxide film}

The corrosion resistance of NAB is attributed to the formation of protective oxide film on NAB. This formation may occur either in air or submerged in corrosive environment like chloride solution. The rate of oxide film growth is much more rapid when fully immersed in corrosive solution that in air. The oxide layer mainly comprises of cuprous oxide $\left(\mathrm{Cu}_{2} \mathrm{O}\right)$ and aluminium oxide or alumina $\left(\mathrm{Al}_{2} \mathrm{O}_{3}\right)$ films, with traces of copper salts and hydrochlorides $\left(\mathrm{Cu}_{2}(\mathrm{OH})_{3} \mathrm{Cl}\right.$ and $\left.\mathrm{Cu}(\mathrm{OH}) \mathrm{Cl}\right)$ that form after long exposures to chloride solutions like $3.5 \% \mathrm{NaCl}$ solutions or seawater. These oxides tend to adhere firmly to the substrate, giving very little permeability to liquid corrodant once formed. The oxide layer formed on the substrate/base metal is mostly aluminium-rich, whereas, the oxide formed in the outer regions is generally richer in copper. The oxide films rich in copper, according to Poggie et al., have mechanical properties similar to those of the parent aluminium bronze and are resistant to mechanical disruption during sliding. They greatly reduce the corrosion rate by decreasing the anodic dissolution reactions of aluminium and copper, hampering not only the ionic transport across the oxide layers, but also decreasing the rate of the cathodic reaction on these oxide layers. The oxide films are also considered resistant to most chemical attack, provide good resistance to flow velocity (up to $22.9 \mathrm{~m} \mathrm{~s}^{-1}$ ), and heal rapidly when damaged especially in a corrosive environment like seawater in the presence of oxygen [24], [25], [30], [34].

These oxide films, especially alumina, are relatively hard and abrasive but brittle and notch sensitive like other ceramics. If the oxide film is breached, the substrate becomes vulnerable to galvanic corrosion [24]. The oxide film formed 
in air was barely visible to the naked eye, but after conducting microstructural analysis under SEM, it was found to be less than $20 \mathrm{~nm}$. Whereas, the oxide film formed in $3.5 \% \mathrm{NaCl}$ solution was found to have a thickness of $1000-1200 \mathrm{~nm}$ (Figure 4(b)). It should be noted that the thick oxide layer formed after 3 months of submersion in $3.5 \% \mathrm{NaCl}$ solution have rough porous surface topography and the thickness of the layer does not form homogenously throughout the surface. This is considered to be due to the inhomogeneous distribution of aluminium and copper, the oxide forming elements in the alloy itself. As reported by Wharton and Stokes, the thickness of the protective oxide films vary with different aluminium content on the phases in aluminium bronzes due to the increased electrical insulation of the region with thicker aluminium oxide [30].

As found by Wharton and Stokes [30], the selective corrosion of the $\kappa_{\text {III }}$-phase can extend up to a depth of 200-300 $\mu \mathrm{m}$ after 6.5 months of immersion. They also found that under crevice corrosion, the crevice inlet sustained attack at the $\alpha$-phase of the eutectoid up to a depth of 20-40 $\mu$ m, while the $\kappa_{I I I}$-phase was increasingly more susceptible further below $40 \mu \mathrm{m}$.

This was verified on cross-sectioning of the NAB sample used for the current research with a thick layer of water-formed oxide layer above the substrate formed after 3 months of immersion in 3.5\% $\mathrm{NaCl}$ solution showing crevice and selective phase corrosion attack $40 \mu \mathrm{m}$ deep below the surface (Figure 4(a) and (b)). The composition of the layer, obtained in EDS, mostly comprised of $\mathrm{Cu}, \mathrm{Al}$ and 0 . Corrosion mainly took place at the $\alpha-\kappa_{I I I}$ lamella eutectoid phase boundaries, and its corroded depth could be as deep as $20 \mu \mathrm{m}$ beneath the exposed surface, propagating deeper into the substrate (as shown in Figure $4(b))$.

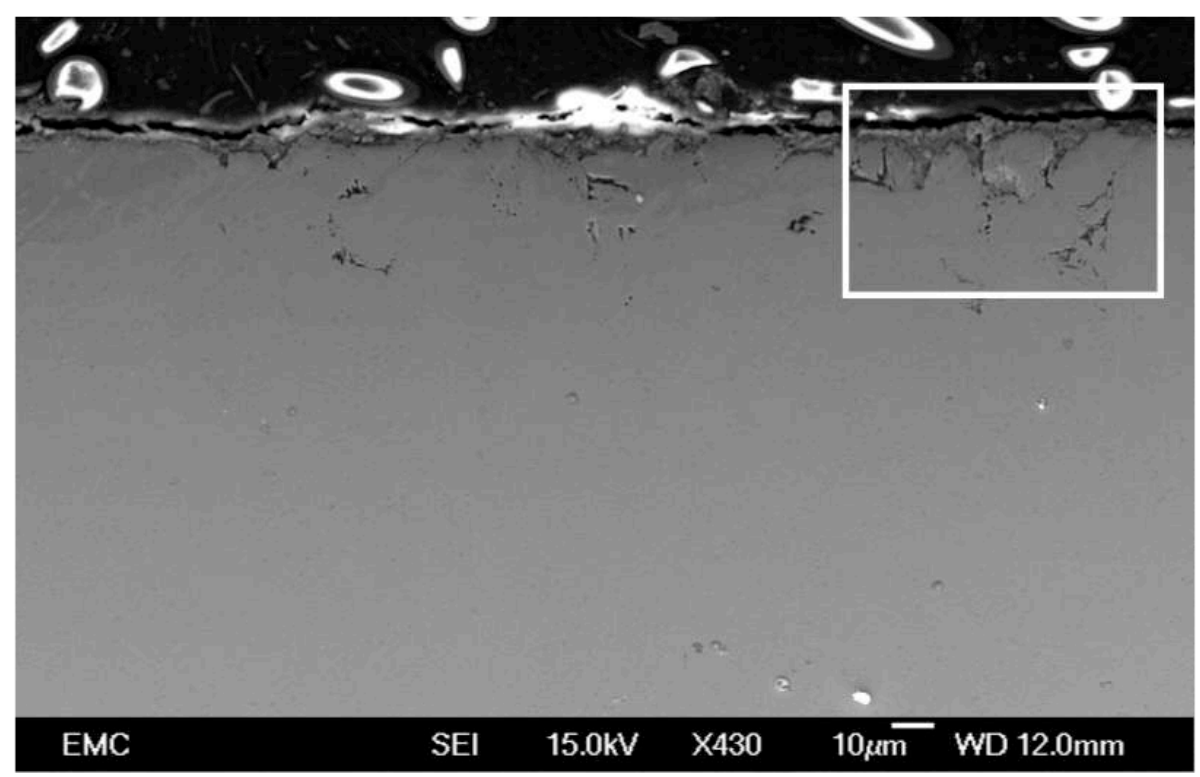

(a) 


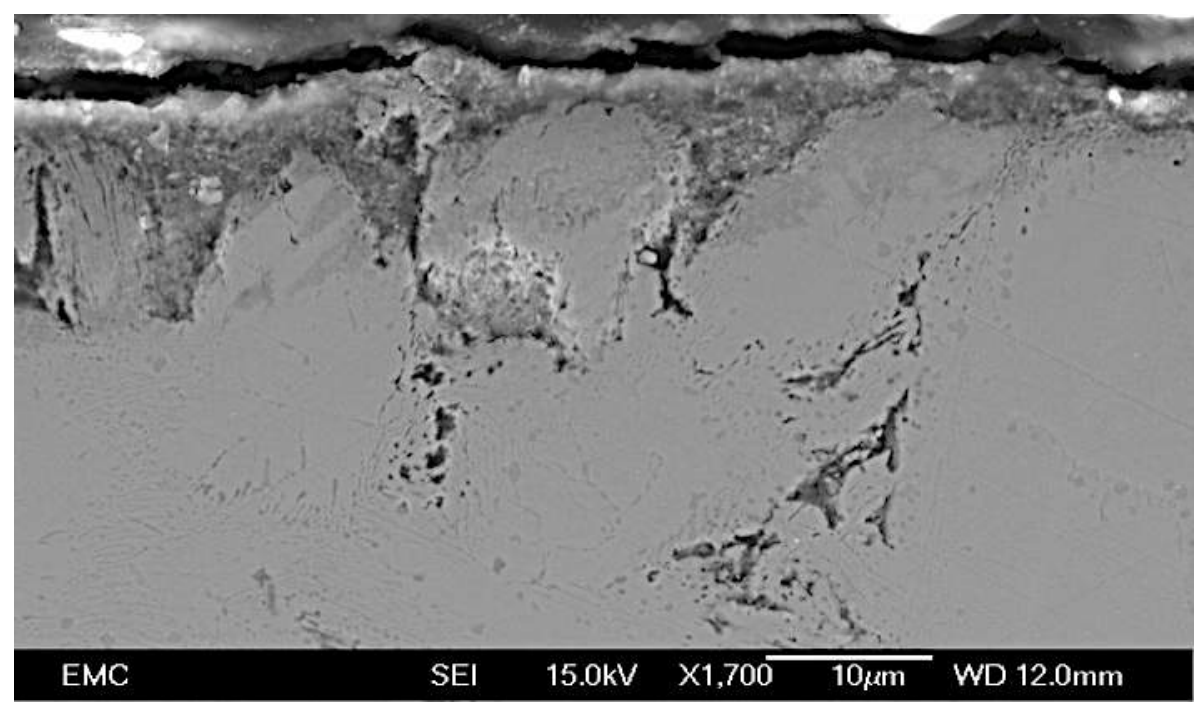

(b)

Fig. 4: SEM images the oxide film cross-section on the NAB substrate after 3 months of immersion in 3.5\% NaCl solution: (a) selective phase corrosion attack reaching up to $40 \mu \mathrm{m}$ in depth; (b) the area selected in (a) showing selective corrosion of the $\kappa_{\text {III }}$ phase under the surface.

\subsection{Experimental procedure}

For the cavitation evaluation, the test samples used were cavitated in the same manner as in ref. [5] under an ultrasonic vibratory cavitation transducer, UIP1000hd, at the tribology laboratory, University of Southampton. The samples were held in a perspex bath using perspex fixture for the indirect cavitation process conforming to the ASTM standard G32-10 [38]. The samples were kept at a constant gap of $2 \mathrm{~mm}$ from the sonotrode tip surface. Figure 5 gives the schematics of the test arrangement [5]. The sonotrode was operated at a frequency of $19.5 \mathrm{kHz}$ and peak-to-peak amplitude of $80( \pm 0.2) \mu \mathrm{m}$.

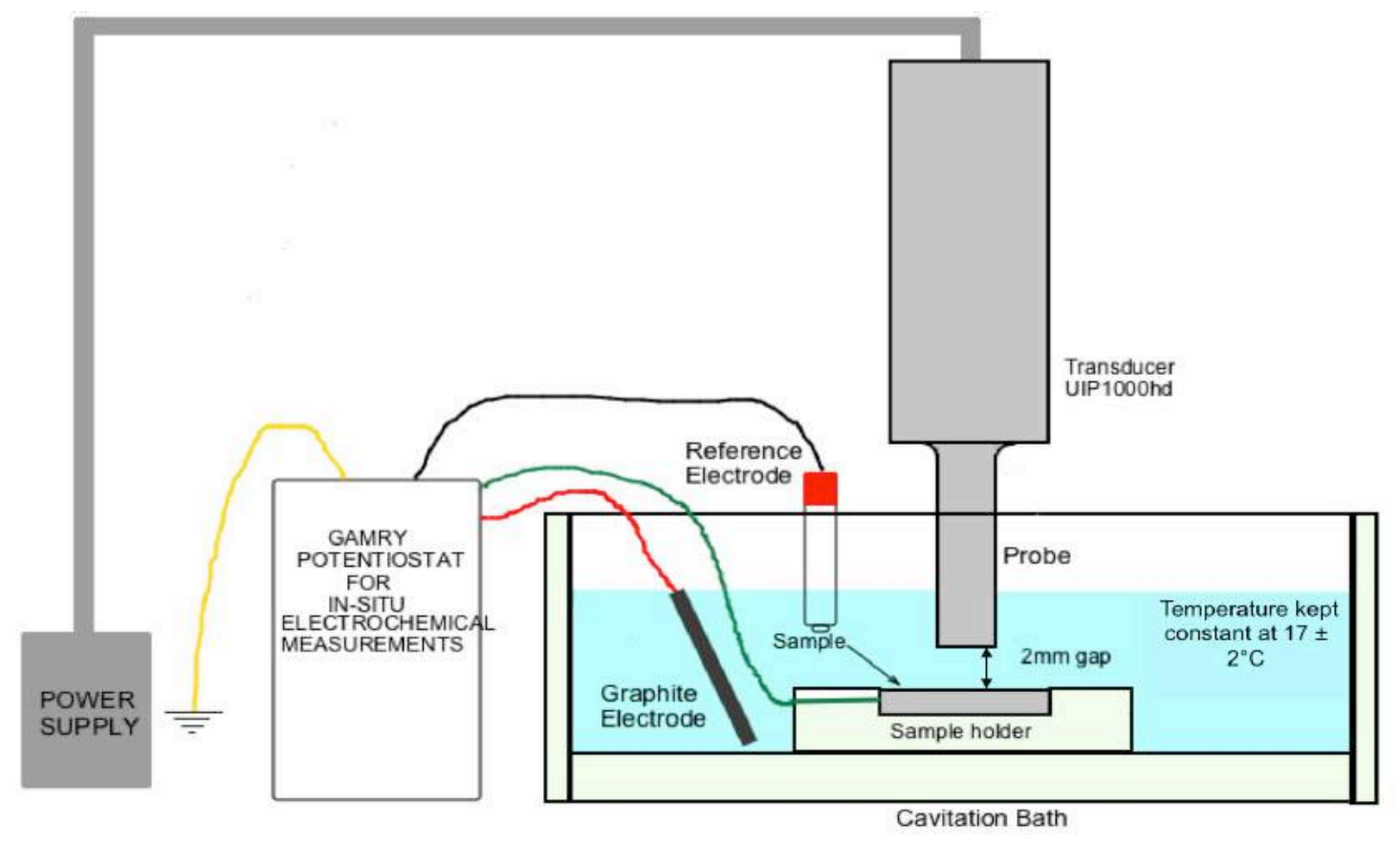


Fig. 5: Schematics of the cavitation rig with specimen connected to the electrochemical potentiostat, GAMRY Ref600, for cavitation erosion and corrosion measurements [5].

The tests were conducted for 1 hour each, and the tip surface of the sonotrode was ground to fine surface finish of up to 0.6 micron after each cavitation test using lathe at the engineering and design manufacturing centre (EDMC) at University of Southampton. The liquid mediums used for the experiments were 5 $\mathrm{L}$ of distilled water and $5 \mathrm{~L}$ of $3.5 \% \mathrm{NaCl}$ solution prepared in the lab for the tests. The temperature and the $\mathrm{pH}$ of the water were monitored to remain constant at a room temperature of $17 \pm 0.5^{\circ} \mathrm{C}$ and $\mathrm{pH}$ of $7.5-8.5$ throughout the experiment.

The electrochemical tests were conducted using the GAMRY Reference 600 potentiostat to monitor and obtain the OCP and polarization curves for the samples. The parameters for conducting the OCP and polarization tests were set and performed in the GAMRY Framework software, whereas and the data obtained were analysed in the GAMRY Echem Analyst software.

The gravimetric weights of the samples were recorded before and after each experiment with suite 500 precision weighing machine for gravimetric analyses $( \pm 0.01 \mathrm{mg}$ ). The samples were analysed for microstructural characterization using JOEL (JSM6500F) scanning electron microscope (SEM) employed for microstructural morphology analysis before and after cavitation.

To investigate the synergy for the two sample types, three different tests were conducted in order to obtain the synergistic results between cavitation wear and corrosion. For the pure corrosion (C) tests, all the samples were subjected to OCP and polarization test in 3.5\% NaCl solution. For pure erosion (E) test the samples were cavitated in $5 \mathrm{~L}$ of distilled water for 1 hour. Finally, for the combined cavitation erosion-corrosion (T), the samples were cavitated in $5 \mathrm{~L}$ of $3.5 \% \mathrm{NaCl}$ solution for 1 hour while subjected to electrochemical tests kept under OCP.

\section{Results and discussions}

\subsection{Electrochemical comparison}

Figure 6 is the OCP curve obtained for NAB with air-formed and water-formed oxide films in pure corrosion and erosion-corrosion in $3.5 \% \mathrm{NaCl}$ solution, where $\mathrm{Vf}$ is the reference potentials in volt. From the electrochemical tests, it was seen that the water-formed oxide filmed had higher passivation for both pure corrosion and cavitation erosion-corrosion. The figure shows that the air-formed filmed NAB reached stability at $-210 \mathrm{mV}$ under pure corrosion, whereas the water formed filmed $\mathrm{NAB}$ reached stability at $-150 \mathrm{mV}$. 


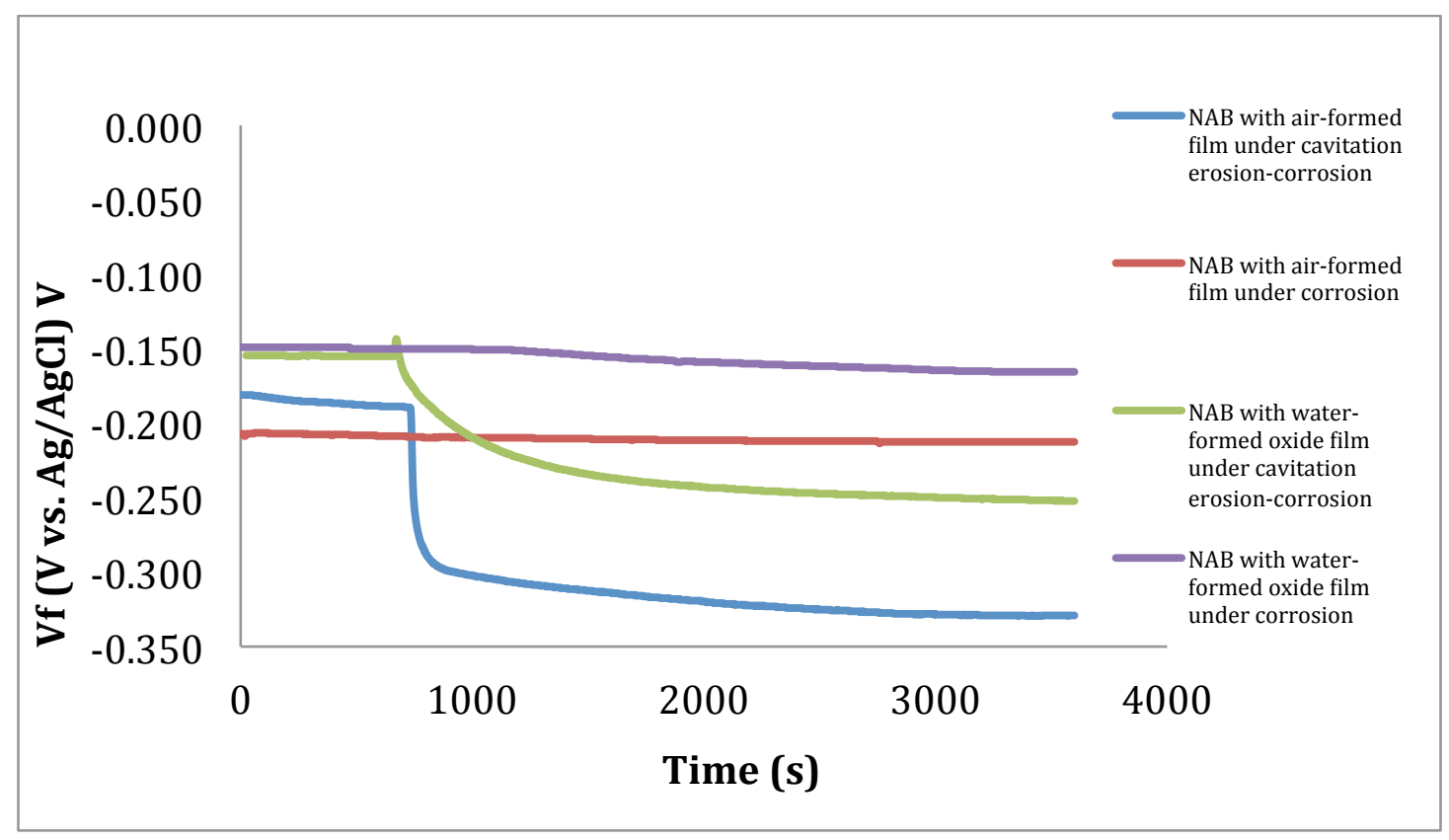

Fig. 6: OCP for NAB with air-formed oxide film and water-formed oxide film in $3.5 \% \mathrm{NaCl}$ solution for 1 hour with and without cavitation.

It was observed that the measured OCP shifted slightly negatively by about $6 \mathrm{mV}$ from $-207 \mathrm{mV}$ to $-213 \mathrm{mV}$ for air-formed film, and by almost $20 \mathrm{mV}$ for waterformed film from $-149 \mathrm{mV}$ to $-165 \mathrm{mV}$ under pure corrosion tests. This indicated that the protective oxide films on both NAB samples were slowly broken down due to localized corrosion, causing selective phase attack, during its immersion in the $3.5 \% \mathrm{NaCl}$ solution. However, there is a dramatic negative shift in OCP upon cavitation impact. The OCP of water formed filmed surface was more anodic by 20 - $50 \mathrm{mV}$ than the air-formed filmed surface.

For the cavitation erosion-corrosion tests, the cavitation was applied to samples held under OCP after 600 seconds. As can be seen from Figure 6, for the airformed filmed samples there was a drastic negative drop observed in the OCP from $-170 \mathrm{mV}$ to about $-300 \mathrm{mV}$ on applying cavitation, while the cavitating NAB reached stability within 120 seconds at a lower potential of $-310 \mathrm{mV}$ [5]. Whereas, for the water-formed oxide filmed NAB the OCP shifted from -151 mV to about $-250 \mathrm{mV}$ before attaining stability, although the negative shift and stability was attained more gradually over time in about 600 seconds.

Therefore, it can be concluded that NAB with water-formed film exhibited better corrosion resistance under static as well as cavitation erosion-corrosion over time. It is also noteworthy that under cavitation impact, the OCP very gradually shifted towards more negative value with time. Both mass transfer and the disruption of the protective layer as well as the material surface by the rapid and violent implosion of cavitation bubbles, observed both on the OCP trends and via microscope, was considered to be the cause of the drastic negative shifts of the corrosion potentials of the materials.

For the pure corrosion test, samples with oxide layers formed under the two different conditions and having an exposed surface area of $6.25 \mathrm{~cm}^{-2}$ were 
subjected to potentiodynamic polarization at a scan rate of $0.167 \mathrm{mV} \mathrm{s}^{-1}$ under static conditions using GAMRY potentiostat in $100 \mathrm{ml}$ of $3.5 \% \mathrm{NaCl}$ solution. Figure 7 plots the two polarization curves comparing the current rate and active regions of the two samples.

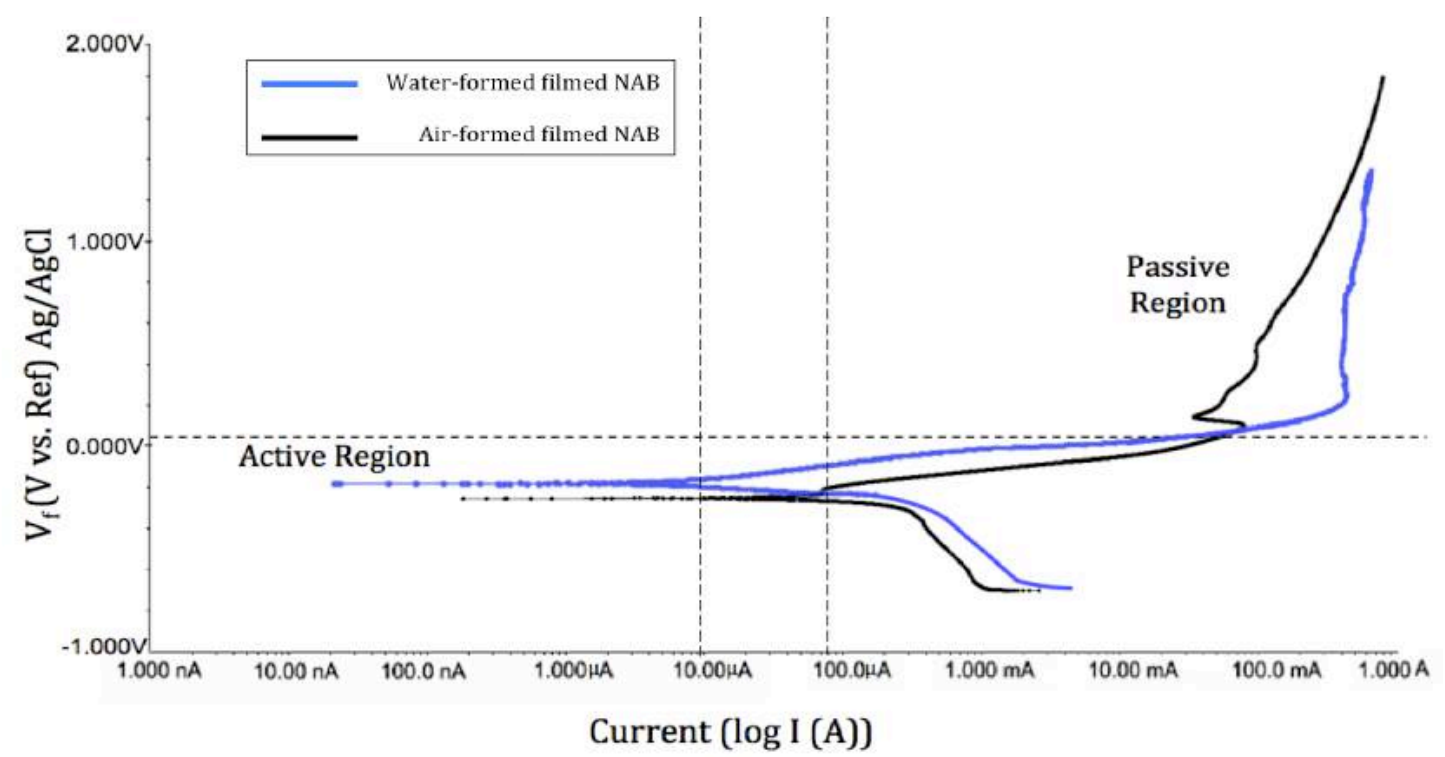

Fig. 7: Polarization curves for NAB with air-formed oxide film and water-formed oxide film in 3.5\% NaCl solution for 6 hours.

From the polarization results obtained, it can be seen that the corrosion current density ( $\mathrm{I}_{\text {corr }}$ ) of water-formed oxide filmed NAB is lower at $1.6 \mu \mathrm{A} \mathrm{cm}^{-2}$ than $\mathrm{I}_{\text {corr }}$ of air-formed oxide filmed NAB at $16.0 \mu \mathrm{A} \mathrm{cm}^{-2}$.

For NAB comprising of $80 \%$ copper, the main corrosion reaction is generally considered to be for copper [30]. Hence, the sample materials were considered to undergo rapid copper dissolution as shown in Equations (8) - (9) taking place in the electrochemical cell:

$\mathrm{Cu}+\mathrm{Cl}^{-} \rightarrow \mathrm{CuCl}+\mathrm{e}^{-}$
$\mathrm{Cu}+2 \mathrm{Cl}^{-} \rightarrow \mathrm{CuCl}_{2}^{-}+\mathrm{e}^{-}$

The corrosion rates of the samples were calculated, which further aided in measuring the subsequent mass loss found using Equation 10.

$$
\text { Mass loss rate }=\frac{3.729 \times 10^{-5} \times \text { Icorr } \times \text { Atomic mass of corroding element }}{\text { number of electrons freed }}
$$

Where, the rate of mass loss is in $\mathrm{mg} \mathrm{cm}^{-2} \mathrm{~h}^{-1}$, the corroding element was considered to be copper, and the number of freed electrons was taken as 2 (from Equations 8 and 9).

Hence, the mass loss values obtained for pure corrosion after polarization are as given in Table 2: 


\begin{tabular}{|c|c|c|}
\hline NAB sample surface & Current density (in $\boldsymbol{\mu A ~ \mathbf { ~ c m } ^ { - 2 } \text { ) }}$ & $\begin{array}{c}\text { Mass loss (in mg) } \\
\text { (from Equation 8) }\end{array}$ \\
\hline Air formed filmed & 16.0 & $0.2 \pm 0.01$ \\
\hline Water formed filmed & 1.6 & $0.02 \pm 0.01$ \\
\hline
\end{tabular}

Table 2: Current density and mass loss obtained for NAB with air-formed oxide film and water-formed oxide film from polarization scanning in 3.5\% $\mathrm{NaCl}$ solution for 6 hours.

\subsection{Microstructural morphology}

For the microstructural analysis of the cavitated surface for air-formed film under SEM, it was found that the soft $\alpha$-matrix, especially surrounding the hard iron-rich $\kappa$ phases, seemed to be most vulnerable to cavitation attack as compared to the $\kappa$ phases and the precipitate-free $\alpha$ zones. The cavity sizes ranged between 10-30 $\mu \mathrm{m}$ in distilled water (see Figure 8(a) and (b)) as also reported in ref [5], especially at the $\alpha$ - $\kappa_{I I I}$ grain boundaries. Whereas, the cavities were recorded to be much larger, $50-80 \mu \mathrm{m}$, for the cavitation erosion-corrosion test in $3.5 \% \mathrm{NaCl}$ solution It was also found that the materials underwent selective cavitation erosion-corrosion attack in $3.5 \% \mathrm{NaCl}$ solution at the $\alpha$ - $\kappa_{I I I}$ phase boundaries as seen in Figure 8(c) and (d); hence the regions with high lamellar $\kappa_{I I I}$ phases were most susceptible. Also seen in Figure 8(d) are $\kappa$-phases exposed due to the surrounding soft $\alpha$ phase being eroded away. 


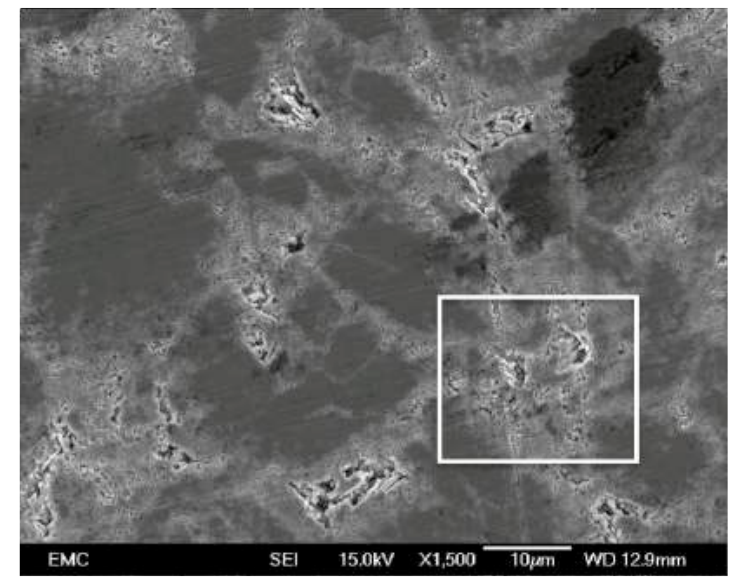

(a)

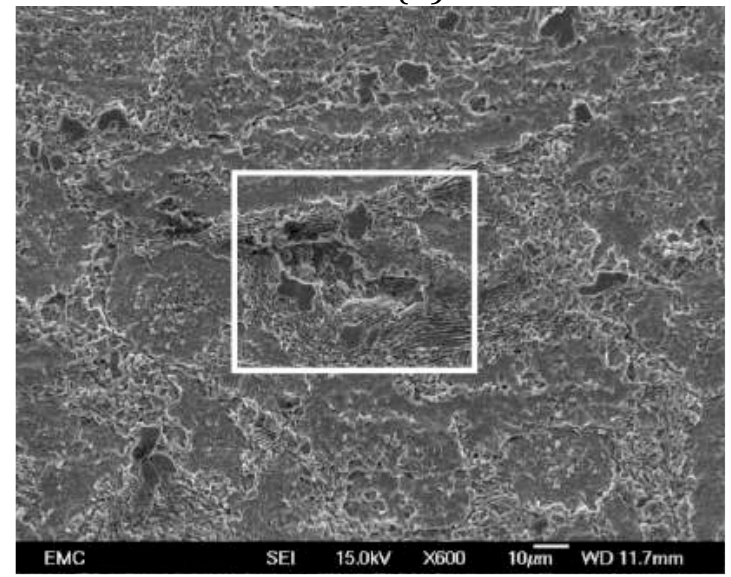

(c)

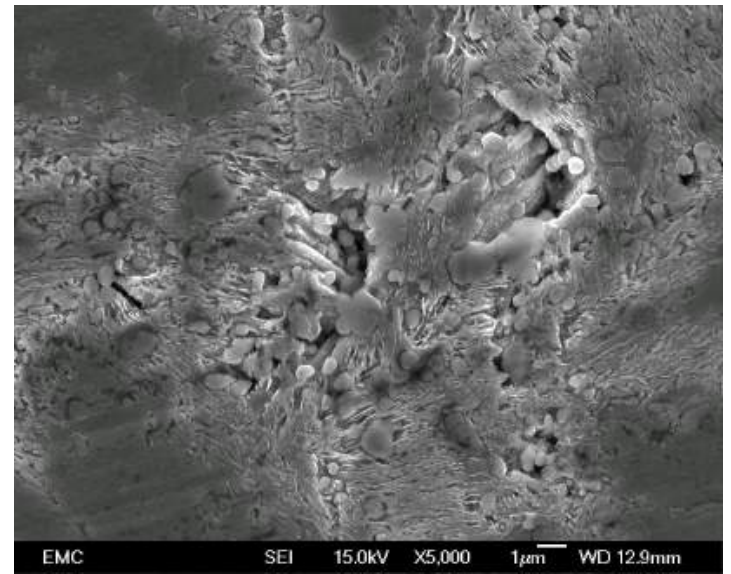

(b)

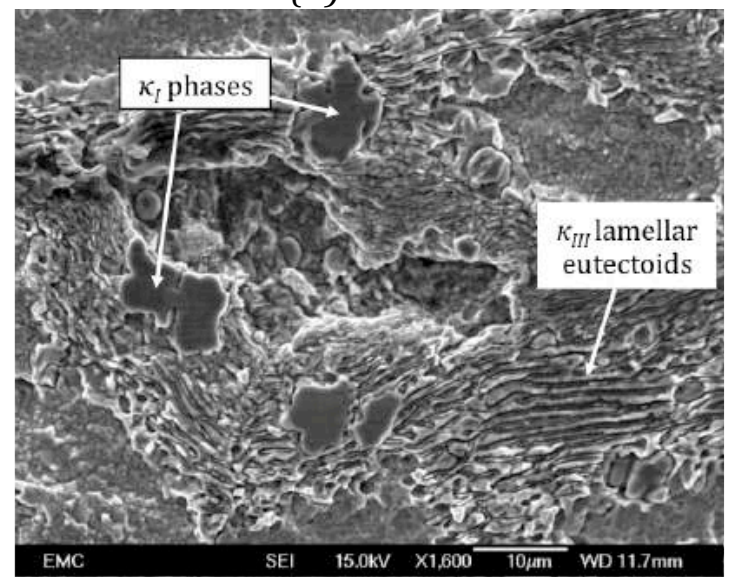

(d)

Fig. 8: SEM images of (a) small selective phase attack on air-formed film at a magnification of $x 1500$ in distilled water; and (b) magnification of the selected area at $x$ 5000; (c) SEM image of a $50 \mu \mathrm{m}$ large cavity on the sample surface undergone cavitation erosion-corrosion in 3.5\% NaCl solution; (d) the magnified image of a cavity in (c) showing selective phase attack at the $\alpha$ - $\kappa$ phase boundaries leaving $\kappa_{I}$ globules and $\kappa_{I I I}$ lamellar phases exposed [17].

The transverse section of the cavitation erosion pattern in an air-formed oxide filmed NAB sample is shown in Figure 9. The cross-sectional imaging confirmed that the adverse site of attack was mostly at the $\alpha-\kappa$ phase boundaries. Once the cavitation erosion took place, several micro-cracks initiated at these erosion sites, and from there on propagated into the microstructure, especially along the $\alpha-\kappa$ grain boundaries. Also, several subsurface cracks were observed, however the origin and mechanism of these cracks are not fully determined. 


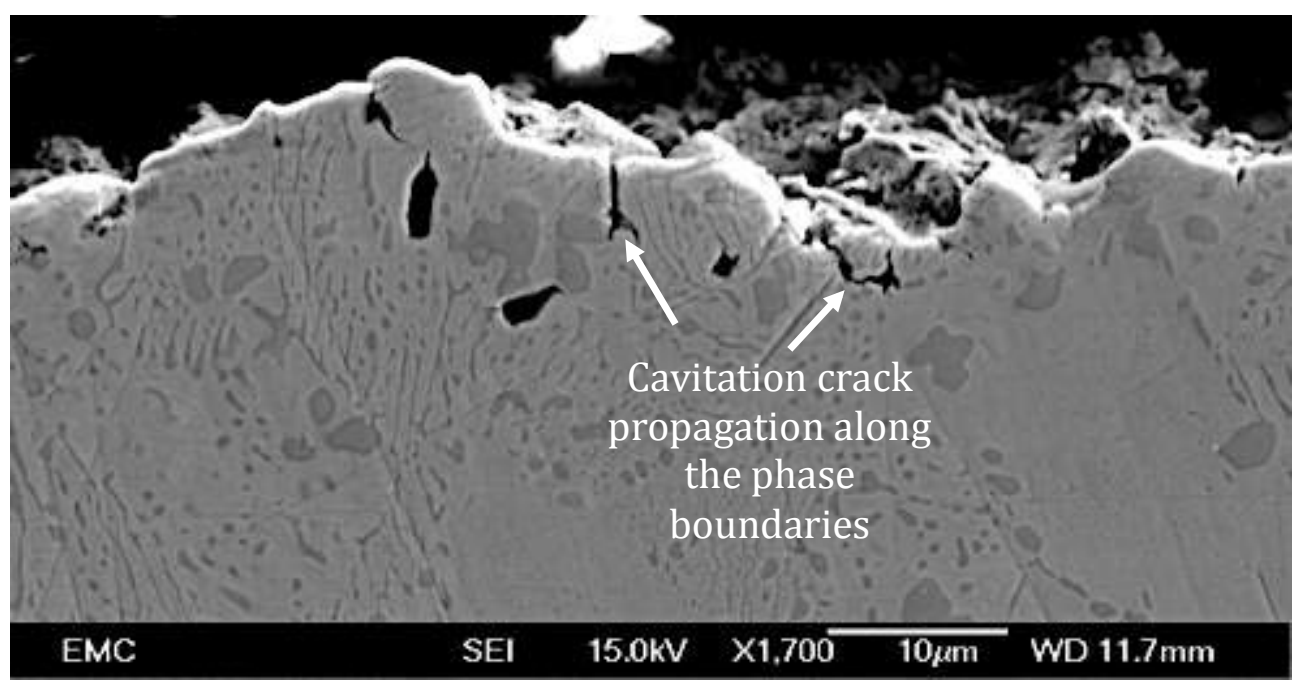

(a)

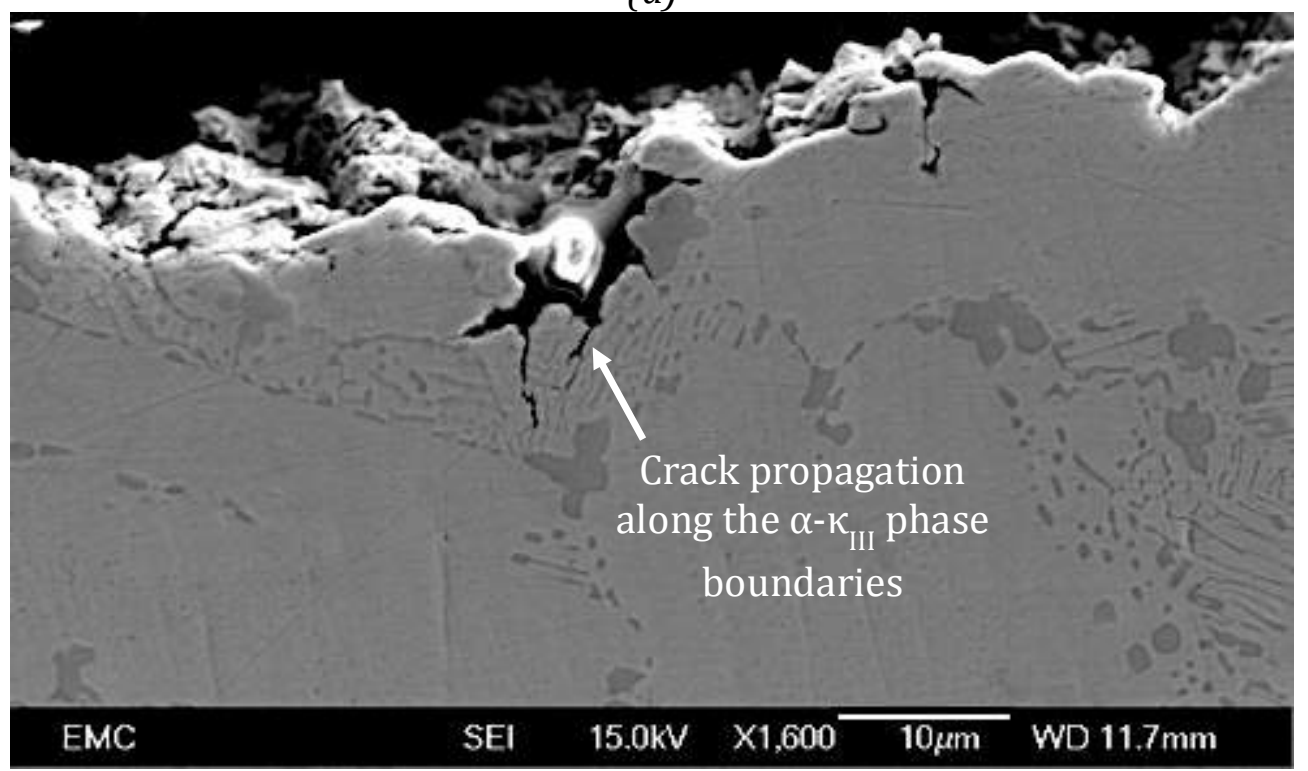

(b)

Fig. 9: SEM images of transverse sections of NAB after 1 hour of cavitation erosioncorrosion test in 3.5\% $\mathrm{NaCl}$ solution with air-formed film showing crack propagation along the $\alpha$ - $\kappa_{I I I}$ phase boundaries and plastic deformation.

Figure 10 (a) and (b) show optical images of the transverse section of an airformed filmed surface cavitated in $3.5 \% \mathrm{NaCl}$ solution for 5 hours. Figure 10 (a) shows a series of cracks formed under the surface up to a depth of $150 \mu \mathrm{m}$ and interesting crack formation along the $\alpha-\kappa$ phase boundaries especially beneath the largest cavity, about $50 \mu \mathrm{m}$ in size. Figure 10 (b) shows the magnified image of the crack feature. There are a number of stresses acting upon the surface, such as the tensile/compressive shear stress, repetitive loading of the cavitation cloud, subsurface shear stress build-up, as well as the material property itself that may mitigate cracks along the weakest grain boundaries, and several subsurface cracks, as seen in Figure 10 (a). The formations of the subsurface cracks are speculated to be due to the interaction between the slip lines of the cu-rich matrix and the hard secondary phases. The $\alpha$-matrix, having an FCC structure follows the preferential $<111>$ slip plane. The subsurface layer generally procures more dislocation than the surface itself. With repetitive or 
cyclic loading there tends to be pile-ups of dislocations along the subsurface layer that leads to the formation of voids. This is further enhanced within the material with multi-phases with differences in the hardness. The dislocation is then said to pile against the hard secondary phases, forming voids primarily due to plastic flow of softer matrix around hard secondary phase particles within the microstructure [39]. This, combined with the accumulate subsurface strain, lower fracture toughness of the softer phase against the hard phases with higher mechanical property gives way to stress concentration at the grain boundaries, which then eventually results in the failure under cyclic impact stress generated by the cavitation clouds. And hence, causing the subsurface cracks.

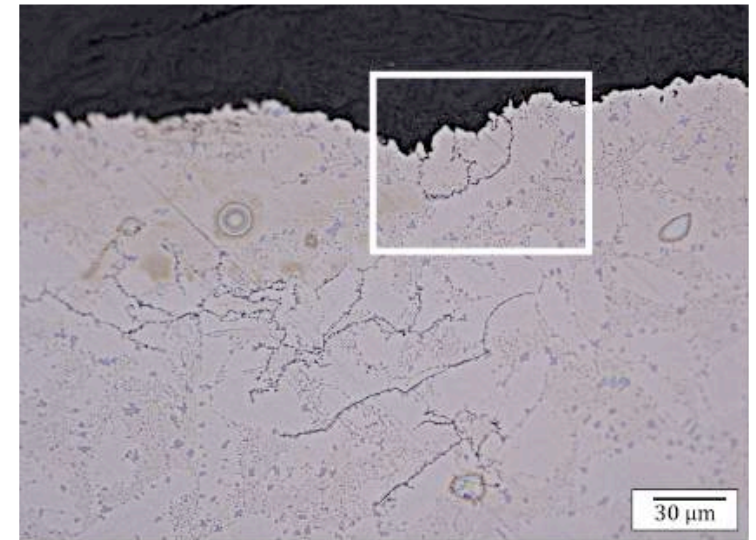

(a)

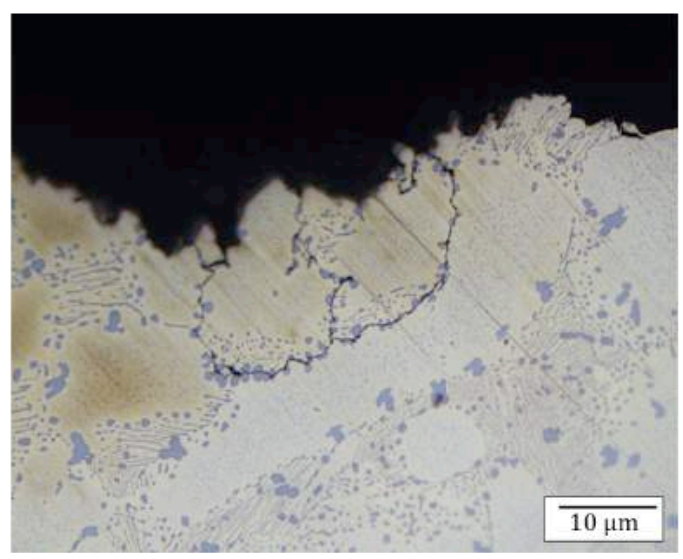

(b)

Fig. 10: Optical images of: (a) dendritic surface and potential subsurface cracks at 200x; and (b) detail of the selected area in Figure 10(a) of surface cracks forming along the grain boundaries at 1200x after 1 hour of cavitation erosion-corrosion test in $3.5 \% \mathrm{NaCl}$ solution.

However, it should not be disregarded that these cracks may in fact be initiating somewhere on the surface and propagating along the weak grain boundaries with low fracture toughness and into the surrounding microstructure. Further detailed sectioning and characterization of these cracks would be required to explain these cracks, their mechanisms and the crack initiation processes.

For the water-formed film, the wear mechanism was found to be same as the airformed film. However, the oxide film formation, the film thickness, and the impact of corrosion in chloride solution played a significant role in the cavitation erosion-corrosion behaviour of NAB immersed in 3.5\% $\mathrm{NaCl}$ solution for 3 months. Figure 11 shows the water-formed un-cavitated oxide film on NAB, where the microstructure of the substrate is not clearly distinguishable. 


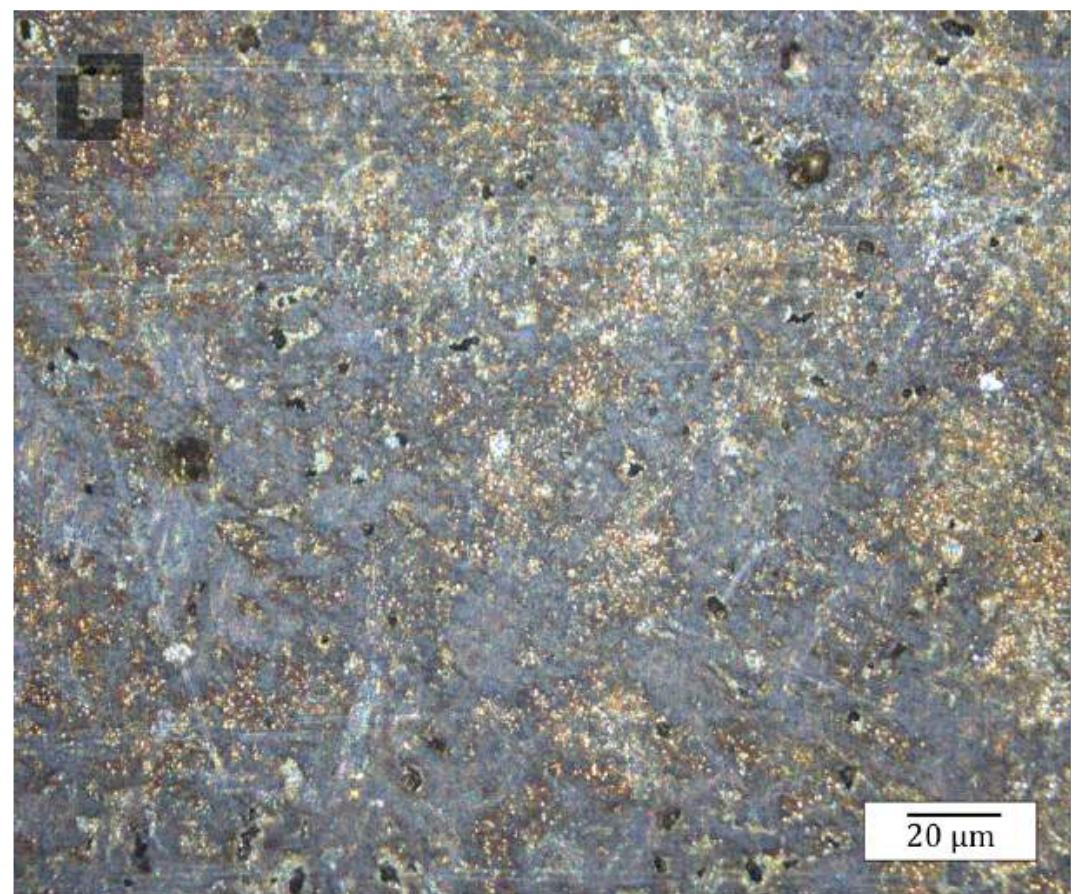

Fig. 11: Image of water-formed oxide filmed NAB surface before cavitation erosion-corrosion.

From the cavitation erosion-corrosion results obtained, it was observed that the phase boundaries, as already weakened by crevice corrosion and selective phase attack, were the first site of attack for cavitation erosion-corrosion. Figure 12 (a) shows the cavitation erosion pattern on the roughened oxide surface, detailing a cavity formed due to the erosion for 1 hour in distilled water. On closer analysis under the SEM, the erosion was seen to expose the $\alpha-\kappa_{I I I}$ phase boundaries under the oxide film, shown in Figures 12 (b).

Figure 12 (c) shows the transverse sections of a cavity on the sample surface after 1 hour of cavitation conducted under pure $\mathrm{E}$ conditions for a water-formed oxide filmed NAB sample. The cavity was found to be of 30- $\mu$ m diameter with a large crack propagating into the microstructure. Figure 12 (d) shows the magnified details of the crack (highlighted in (c)) revealing the crack growth and propagation into the microstructure along the $\alpha-\kappa_{I I I}$ phase boundaries. Figure 12 (c) and (d) show the cavitation erosion pattern on the surface, detailing a cavity formed due to the erosion of the $\alpha$ phase at the $\alpha$ - $\kappa$ phase boundary, leaving globules and lamellar structures of $\kappa_{I}$ and $\kappa_{I I I}$ phases exposed. 


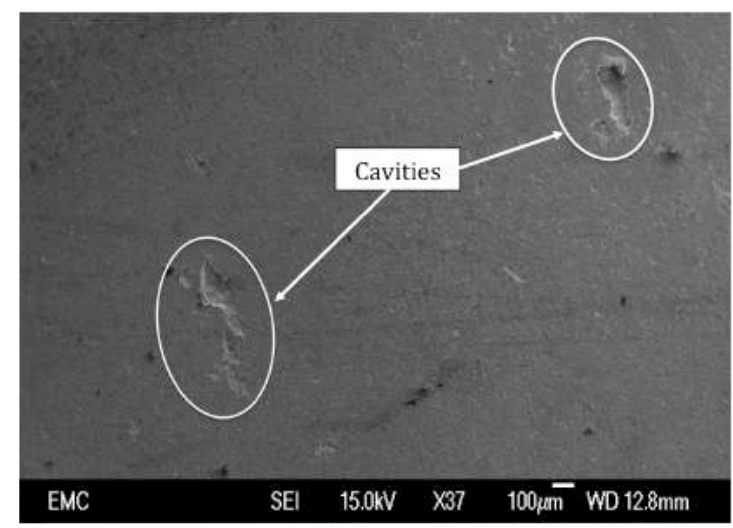

(a)

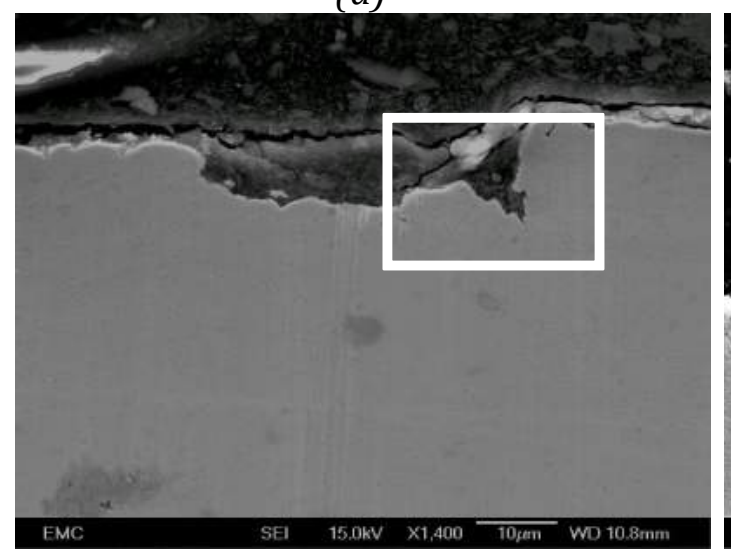

(c)

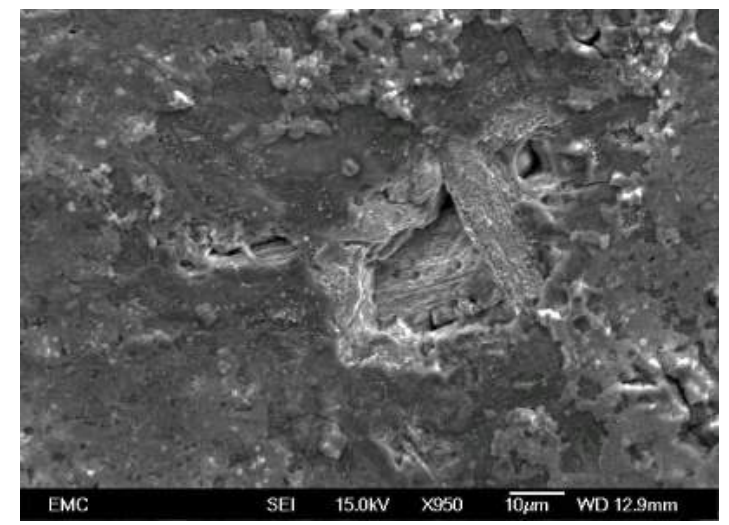

(b)

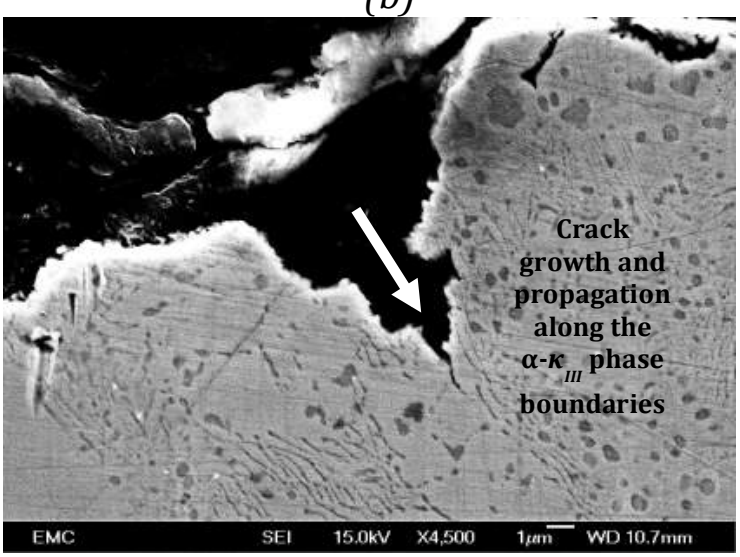

(d)

Fig. 12: SEM images of water-formed oxide filmed NAB sample under pure $E$ conditions: (a) cavities formed on the sample surface after 1 hour of cavitation erosion-corrosion; (b) magnified image of the cavities on the surface; (c) transverse-sections of a cavity at x1400; (b) detailed magnified image of a cavity in

(d) exhibiting crack growth and propagation along the $\alpha-\kappa_{\text {III }}$ phase boundaries.

The wear scar images obtained after 1 hour of cavitation erosion, with the combined effect of corrosion (T) in 3.5\% $\mathrm{NaCl}$ solution showed more aggressive wear scar and surface roughness, as seen in Figure 13, illustrating the various different phases within the microstructure. It is evident from the figure that the softer matrix has been eroded and detached, leaving behind small islands of harder iron-rich $\kappa$ phases exposed, especially at the highest concentration of grain boundaries. Islands of $\kappa_{I}$ were seen at the erosion boundaries, whereas threads of $\kappa_{I I I}$ were left exposed at regions with high $\alpha$ - $\kappa_{I I I}$ eutectoid phases. Furthermore, particulates of $\kappa_{I V}$ phase were also seen to become more prominent due to the $\alpha$-phase erosion at the phase boundaries. 


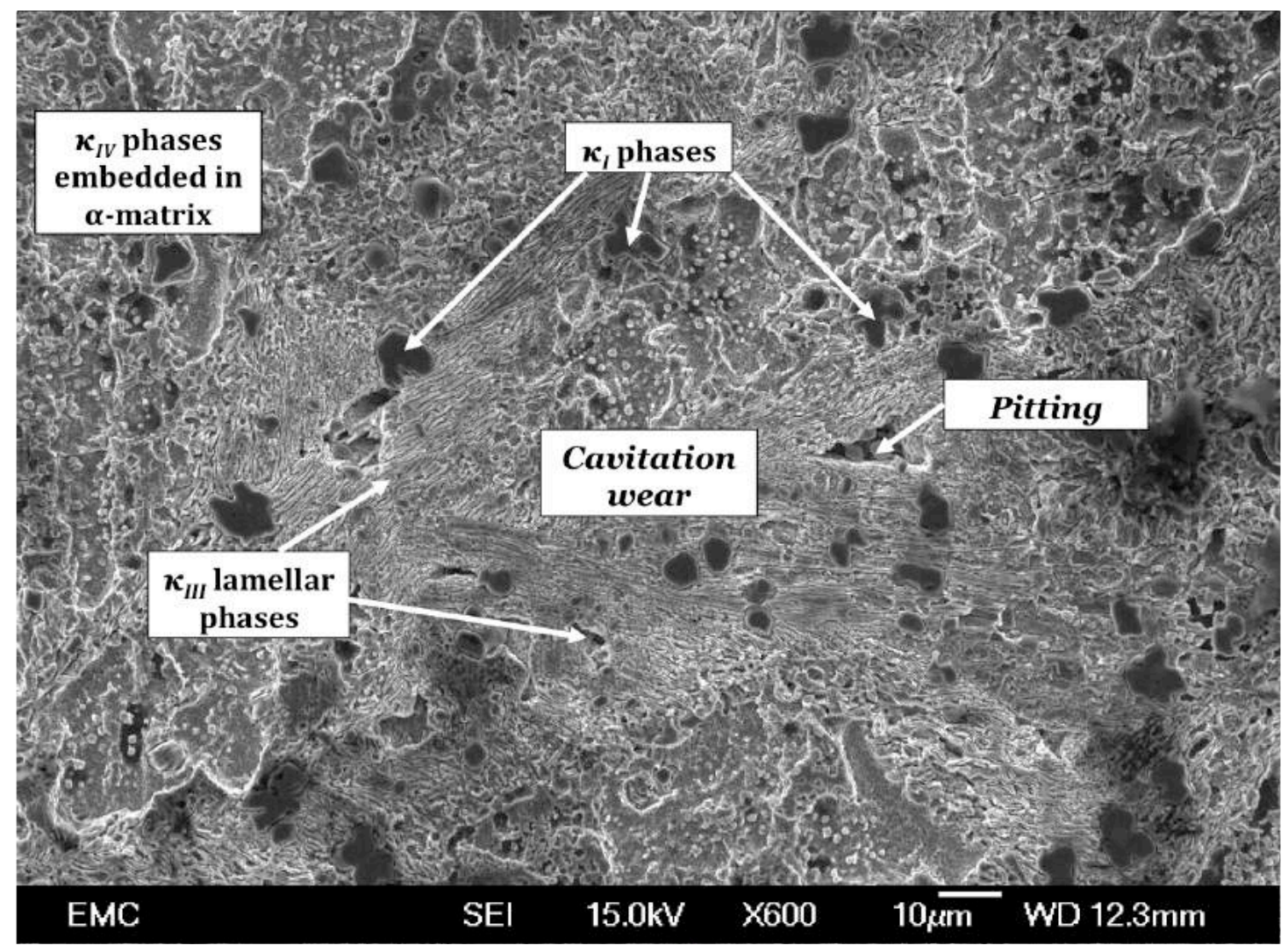

Fig. 13: SEM image of the eroded surface of NAB sample with water-formed oxide film after combined cavitation erosion-corrosion test conducted in $3.5 \% \mathrm{NaCl}$ solution for 1 hour.

For both $\mathrm{E}$ and $\mathrm{T}$ conditions, it was seen that the water-formed oxide filmed NAB surface suffered similar erosion trend. The lamellar eutectoid phase boundaries were seen to be most suceptible to corrosion attack, making them further vulnerable to wear via cavitation erosion. Hence, the roughness observed was the highest in these phase boundaries. In Figure 14(a) the phases can be easily distinguished, especially after cavitation erosion-corrosion due to selective phase attack and wear at the $\alpha-\kappa_{I I I}$ as well as $\alpha$ - $\kappa_{I V}$ phase boundaries, with the exposed $\kappa_{I V}$ phases imbedded into the soft matrix (Figure 14(b)). 


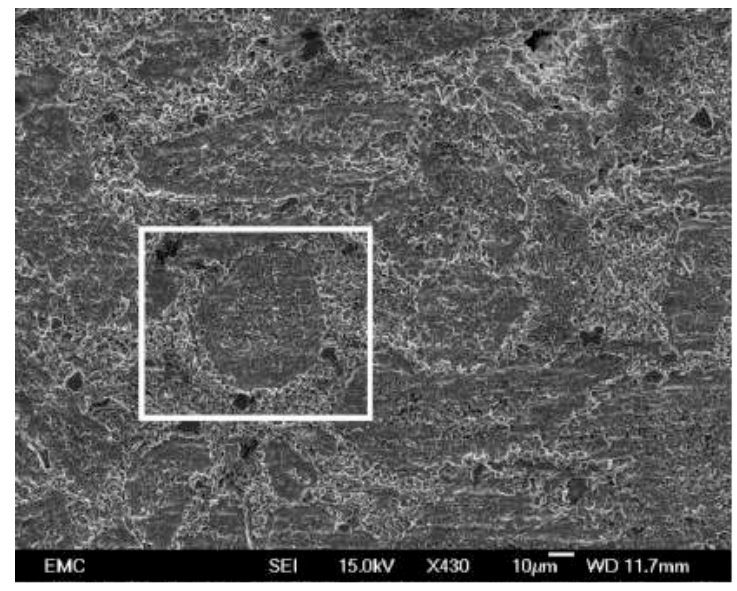

(a)

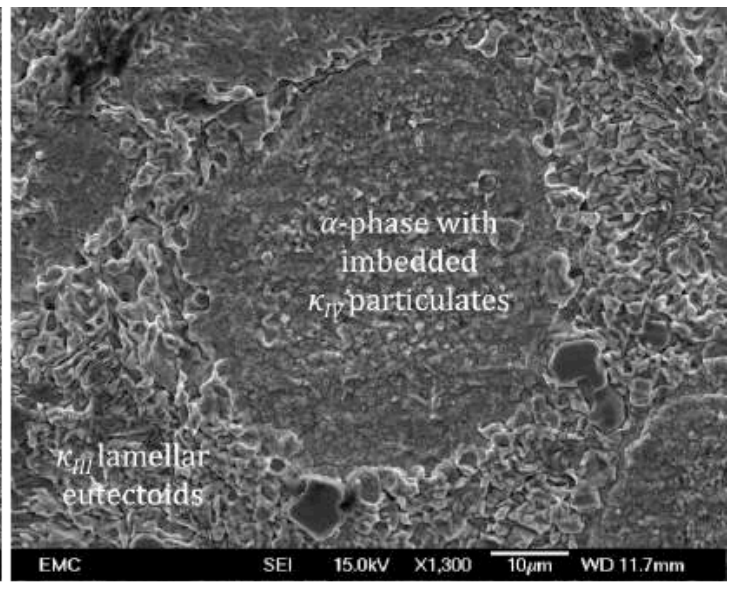

(b)

Fig. 14: SEM images of the distinguished phase erosion of the oxide filmed sample in $3.5 \% \mathrm{NaCl}$ solution after 1 hour of cavitation.

Figures 15(a) and (b) show the transverse sections of the sample surface after 1 hour of cavitation erosion-corrosion test for the water-formed oxide filmed NAB sample. The cavities were found to be of about 50-80 $\mu \mathrm{m}$ in diameter. Figure 15 exhibits a large crack propagating into the microstructure along the $\alpha$ - $\kappa_{I I I}$ phase boundaries.

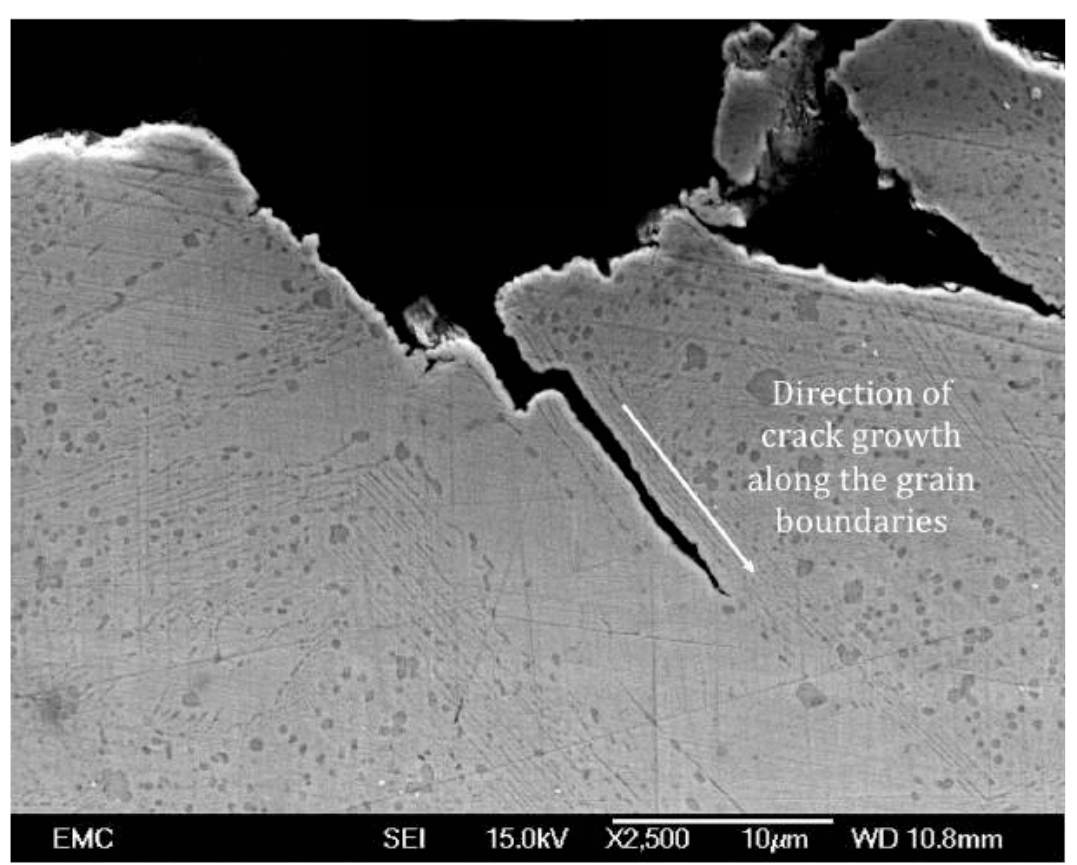

Fig. 15: SEM images of transverse sections of NAB after 1 hour of cavitation erosion-corrosion test in 3.5\% NaCl solution with water-formed film showing cracks propagating along the lamellar eutectoid grain boundaries.

As seen from the microstructural analyses obtained, it was concluded that the main synergistic mechanism at play for the test materials was the $\Delta \mathrm{E}$ mechanism, where the erosion rate of the substrate was enhanced due to selective corrosion attack at the grain boundaries under $\mathrm{T}$. This was more prominent for NAB with water-formed film due to the pre-exposure to corrosion environment, subjecting to corrosion prior to cavitation. 


\subsection{Synergy measurement}

Using Equation 1, the synergy was calculated for the two types of oxide filmed NAB samples. The results comparing synergism for samples with air-formed as well as water-formed oxide films are tabulated in Table 3.

\begin{tabular}{|c|c|c|c|c|c|}
\hline $\begin{array}{c}\text { NAB } \\
\text { sample } \\
\text { with }\end{array}$ & T (mg) & E (mg) & C (mg) & $\begin{array}{c}\begin{array}{c}\mathrm{S}=\mathrm{T}-(\mathrm{E}+\mathrm{C}) \\
(\mathrm{mg})\end{array} \\
\text { From } \\
\text { Equation } 1\end{array}$ & $(\mathrm{~S} / \mathrm{T}) \times 100$ \\
\hline $\begin{array}{l}\text { Air-formed } \\
\text { oxide film }\end{array}$ & $\begin{array}{c}1.48 \pm \\
0.02\end{array}$ & $\begin{array}{c}1.00 \pm 0.05 \\
\text { (in Distilled } \\
\text { water) }\end{array}$ & $\begin{array}{l}0.2 \pm \\
0.01\end{array}$ & $\begin{array}{l}0.28 \pm \\
0.08\end{array}$ & $19 \%$ \\
\hline $\begin{array}{l}\text { Water- } \\
\text { formed } \\
\text { oxide film }\end{array}$ & $\begin{array}{c}24.39 \pm \\
2.00\end{array}$ & $\begin{array}{c}7.34 \pm 0.30 \\
\text { (in Distilled } \\
\text { water }\end{array}$ & $\begin{array}{l}0.02 \pm \\
0.01\end{array}$ & $\begin{array}{c}17.03 \pm \\
2.30\end{array}$ & $70 \%$ \\
\hline
\end{tabular}

Table 3: Synergism summary for NAB samples with oxide films formed under air and water.

As seen in Table 3, the total mass loss incurred under the combined effect of cavitation erosion and corrosion for NAB samples with water-formed film was much higher (almost 20 times) than the mass loss observed for air-formed oxide filmed sample. Also, the mass loss incurred in distilled water for the waterformed film was significantly lower than that found under $T$ by about 5.6 times for water-formed film. The resultant synergy calculated for samples with waterformed film was found to be about 2.2 times higher at 70\% than the synergy calculated for samples with air-formed film (19\%).

Air-formed filmed NAB samples performed better than the water-formed filmed NAB samples under $\mathrm{E}$ and $\mathrm{T}$ conditions. This may be attributed to the weakening of the substrate microstructure, sans the removal of the protective oxide layer during cavitation, due to the pre-existing selective phase attack and crevice corrosion induced by 3 months of immersion in $3.5 \% \mathrm{NaCl}$ solution. However, the water-formed filmed NAB showed much higher resistance to corrosion than air-formed filmed NAB, owing to its thick protective oxide layer.

Comparing the synergy results with the studies conducted before, in the studies conducted by Wood and Fry [6] the synergy was found to range between 10 $29 \%$ for copper, and $30-50 \%$ for $\mathrm{Cu}-\mathrm{Ni}$ alloys. They investigated the fundamental mechanisms of the synergistic effect of cavitation erosion and corrosion for copper and cupro-nickel alloys in seawater. These results were measured using the depth of penetration method in seawater after 4.5 hours at different overpotentials of $5-100 \mathrm{mV}$. The tests were conducted in an all-plastic cavitation tunnel comprising of a $60^{\circ}$ symmetrical wedge cavitation source. The specimens of $10 \times 20 \mathrm{~mm}$ working section were held under potentiostatic control in a flowing seawater system at an upstream flow velocity of $14.7 \mathrm{~m} \mathrm{~s}^{-1}$. It 
was hence concluded that the synergistic effect was most marked when the cavitation erosion occurred in presence of mild corrosion with $50-70 \%$ of the damage caused due to pure erosion only.

In another study, Kwok, Cheng and Man [40] investigated the synergistic effect of cavitation erosion and corrosion of copper-based alloys and bronze, among many other engineering alloys with the help of a $20 \mathrm{kHz}$ ultrasonic vibrator at an amplitude of $30 \mu \mathrm{m}$ in distilled water and in $3.5 \% \mathrm{NaCl}$ solution at a temperature of $23^{\circ} \mathrm{C}$. They calculated the synergy via mean depth of penetration rate method and concluded that the cu-based alloys had a synergy percentage of $2.7-4.5 \%$ with $95-97 \%$ of the total damage attributed to pure erosion only. It was also found that corrosion only played a minor role of about $0.1-1.8 \%$ in the overall cavitation erosion-corrosion for copper-based alloys.

Whereas, in the study reported by Barik, Wharton, Wood, et. al. [25], [41] the authors reported negative synergy for NES 747 part 2 NAB. They performed sand slurry jet impingement solid particle erosion-corrosion of NES 747 part 2 NAB samples, conducted on a rig with a horizontal jet of salt solution impinging the NAB sample at $90^{\circ}$ with silica sand particles of $135 \mu \mathrm{m}$ or $235 \mu \mathrm{m}$ mean sizes at $3 \% \mathrm{w} / \mathrm{w}$ concentration. E values were obtained by subjecting the samples to $\mathrm{CP}$ at $200 \mathrm{mV}$ below the corrosion potential under erosion-corrosion conditions. Flow corrosion and total combined loss rates were determined without the addition of solids and CP respectively. They observed strain hardening as the cause of the negative $S$ value layer, sectioning the erosion scars and looking in to the subsurface microstructure and its depth profile. The increase in strain hardening also reduced the erosion rate under $\mathrm{T}$ conditions. They concluded that corrosion in fact enhanced plastic flow, thereby increasing strain in the near surface as compared to the pure erosion conditions [25].

These results, although informative, were measured via different means under varying conditions, and hence cannot be readily compared to the results obtained in the current study, however, a relative comparison can be drawn based on the results obtained, such as in all the cases, erosion had higher contribution upon synergy.

From the results obtained, it can be concluded that the oxide film, being porous and brittle, erode away much faster than the substrate, causing higher material loss under pure erosion for substrate with water-formed oxide film when compared to substrate with air-formed oxide film. And under the combined effect of cavitation erosion and corrosion in a chloride solution, it undergoes higher copper dissolution and hence, further increases material loss due to the combined impact of $\mathrm{E}$ and $\mathrm{C}$.

Additionally, an interesting observation made from Table 3 was the influence of $\Delta \mathrm{E}$, corrosion-enhanced erosion, for both the samples. This can be seen numerically from the increase in mass loss value under $\mathrm{T}$ when compared to the individual $\mathrm{E}$ and $\mathrm{C}$ values, giving a higher $\Delta \mathrm{E}$ contribution towards synergy. Thus, further validating the results that were acquired from the microstructural analyses of the test materials. Whereas, the $\mathrm{E}$ and $\mathrm{T}$ results obtained showed that 
the influence of corrosion on cavitation in fact reduced the mass loss, when compared to the mass loss obtained under E.

This suggests that 3 months immersion of NAB in $3.5 \% \mathrm{NaCl}$ solution caused up to $50-\mu \mathrm{m}$ deep selective phase attacks in the $\alpha$ - $\kappa_{I I I}$ eutectoid phase boundaries, resulting in sponge like porous surface layer. This in turn resulted in the waterformed oxide filmed NAB samples to be more susceptible to cavitation erosioncorrosion than NAB with air-formed oxide film, giving higher mass loss under $\mathrm{E}$ and $\mathrm{T}$. The synergy was hence higher for the water-formed filmed NAB, putting the sample at higher risk of damage induced by combined impact of cavitation erosion and corrosion. In theory, this would deem NAB unfit as marine propeller materials as the marine propellers dock and function in the marine environment throughout their service lives. However, in reality, the propellers may not be subjected to cavitation at such high intensities as under the ultrasonic transducer. Also, in practical usage, the oxide films formed on the propellers get enough intervals for the damaged oxide films to heal, re-instating their good corrosion properties.

\section{Conclusion}

The investigation of synergy conducted for NAB samples with oxide films formed under the two different conditions, air and immersion in $3.5 \% \mathrm{NaCl}$ solution concluded that:

- Both the types of NAB samples had measurable synergy under cavitation erosion and corrosion. The synergy was calculated to be at $70 \%$ for water-formed filmed NAB, whereas, it was about $19 \%$ for the air-formed filmed samples.

- Thick layer of 1-1.2 $\mu$ m oxide film comprising mainly of $\mathrm{Al}_{2} \mathrm{O}_{3}$ and $\mathrm{Cu}_{2} \mathrm{O}$ were found on the NAB sample with oxide film formed after 3 months of immersion in $3.5 \% \mathrm{NaCl}$ solution.

- The water-formed filmed sample underwent higher mass loss than the sample with air formed oxide film. NAB samples with both types of oxide films underwent selective phase attack at mainly the $\kappa_{I I I}$ phases and the $\alpha$ $\kappa_{I I I}$ eutectoid phase boundaries.

- SEM analyses revealed that the wear mechanisms of the cavitated sample surfaces with both air and water formed oxide films were found to be similar in nature with the first site of attack to take place at the $\alpha-\kappa_{I I I}$ eutectoid phase boundaries.

- The selective phase attack and corrosion of NAB immersed in $3.5 \% \mathrm{NaCl}$ solution was more prominent due to the presence of chloride with the corroded depth reaching up to 20-50 $\mu$ m beneath the exposed surface, propagating deeper into the substrate.

- The sites of most aggressive attacks exhibited large cracks propagating into the microstructure along the $\alpha$ - $\kappa_{I I I}$ phase boundaries, hence the regions with high lamellar $\kappa_{I I I}$ phases were most susceptible to wear, crack initiation and propagation. 
- Electrochemical results indicated that the OCP of water formed filmed surface was more anodic by $20-50 \mathrm{mV}$ than the air-formed filmed surface.

- Both samples sifted negatively on the application of cavitation while conducting OCP, before reaching stability again. The water-formed film reached stability much more gradually in $600 \mathrm{sec}$ than the air-formed film that reached stability within $100 \mathrm{sec}$.

\section{Reference:}

[1] G. E. Totten, D. K. Wills, and D. G. Feldmann, Eds., Hydraulic Failure Analysis: Fluids, Components, and System Effects, Issue 1339, 1st ed., vol. 3. Philadelphia: ASTM International, 2001.

[2] J. S. Carlton, "Marine propellers and propulsion," in Bay Propeller, Second., 2007, pp. 382-393.

[3] A. Al-Hashem and W. Riad, "The role of microstructure of nickelaluminium-bronze alloy on its cavitation corrosion behavior in natural seawater," Mater. Charact., vol. 48, no. 1, pp. 37-41, Feb. 2002.

[4] R. J. K. Wood, J. Basumatary, and M.-H. Evans, "Energy-Related Tribocorrrosion Research At The National Centre For Advanced Tribology at Southampton (nCATS)," Second International conference on tribology, 2011. .

[5] J. Basumatary, M. Nie, and R. J. K. Wood, "The Synergistic Effects of Cavitation Erosion-Corrosion in Ship Propeller Materials," J. Bio- TriboCorrosion, vol. 1, no. 2, p. 12, Mar. 2015.

[6] R. J. K. Wood and S. A. Fry, "The Synergistic Effect of Cavitation Erosion and Corrosion for Copper and Cupro-Nickel in Seawater," J. Fluids Eng., vol. 111, no. 3, pp. 271-277, 1990.

[7] "ASTM G119 - 16 Standard Guide for Determining Synergism Between Wear and Corrosion," ASTM international, 2016. [Online]. Available: http://www.astm.org/cgi-bin/resolver.cgi?G119-09(2016). [Accessed: 07Jun-2014].

[8] R. J. K. Wood and S. P. Hutton, "The synergistic effect of erosion and corrosion: published results," Wear, vol. 140, pp. 387-394, 1990.

[9] J. Malik, I. H. Toor, W. H. Ahmed, Z. M. Gasem, M. A. Habib, R. Ben-Mansour, and H. M. Badr, "Investigations on the corrosion-enhanced erosion behavior of carbon steel AISI 1020," Int. J. Electrochem. Sci., vol. 9, no. 12, pp. 6765-6780, 2014.

[10] R. Malka, D. A. Gulino, and M. Technology, "Erosion corrosion and synergistic effects in disturbed liquid-particle flow," Corros. Nacexpo, no. 6594, 2006.

[11] Z. B. Zheng and Y. G. Zheng, "Erosion-enhanced corrosion of stainless steel and carbon steel measured electrochemically under liquid and slurry impingement," Corros. Sci., vol. 102, pp. 259-268, Jan. 2016. 
[12] S. Aribo, R. Barker, X. Hu, and A. Neville, "Erosion-corrosion behaviour of lean duplex stainless steels in 3.5\% $\mathrm{NaCl}$ solution," Wear, vol. 302, no. 1-2, pp. 1602-1608, 2013.

[13] E. A. Culpan and G. Rose, "Microstructural characterization of cast nickel aluminium bronze," J. Mater. Sci., vol. 13, no. 8, pp. 1647-1657, Aug. 1978.

[14] F. Hasan, J. Iqbal, and N. Ridley, "Microstructure of as-cast aluminium bronze containing iron," Mater. Sci. Technol., vol. 1, no. 4, pp. 312-315, 1985.

[15] K. B. Faires, "Characterization Of Microstructure And Microtexture In Longitudinal Sections From Friction Stir Processed Nickel-Aluminum Bronze," North Carolina State University, 2003.

[16] A. Jahanafrooz, E. Hasan, G. W. Lorimer, and N. Ridley, "Microstructural Development in Complex Nickel-Aluminum Bronzes," Metall. Trans., vol. 14, no. October, pp. 1951-1956, 1983.

[17] J. Basumatary and R. J. K. Wood, "Different methods of measuring synergy between cavitation erosion and corrosion for nickel aluminium bronze in 3.5 \% NaCl solution," Submitt. to Tribol. Int., pp. 1-26, 2017.

[18] N. E. Christensen, J. Kudrnovský, and C. O. Rodriguez, "Metamagnetic behavior in Fe3Si and Fe3Al," Int. J. Mater. Sci., vol. 1, pp. 1-15, 2007.

[19] H. S. Cambell, "Aluminium bronze alloys - corrosion resistance guide," no. 80. Copper Development Association, p. 30, 1981.

[20] B. Wallén, “Corrosion of Duplex Stainless Steels in Seawater," 1998.

[21] "Corrosion: Galvanic Corrosion," Specialty Steel Industry of North America. [Online]. Available: http://www.ssina.com/corrosion/galvanic.html. [Accessed: 12-Sep-2013].

[22] F. King, "Corrosion Resistance of Austenitic and Duplex Stainless Steels in Environments Related to UK Geological Disposal A Report to NDA RWMD," Cumbria, 2009.

[23] J. H. Horwath, "Why Nickel Aluminum bronze for sea water pumps," Ampco Pumps Company, 2002. [Online]. Available: http://www.ampcopumps.com/media/1881/Why_NiAlBz_For_Saltwater. pdf.

[24] H. Meigh, "Cast and Wrought Aluminium Bronzes: Properties, Processes and Structure," Inst. Mater. 1 Carlt. House Terrace, London, SW 1 Y 5 DB, UK, 2000. 404, 2000.

[25] J. A. Wharton, R. C. Barik, G. Kear, R. J. K. Wood, K. R. Stokes, and F. C. Walsh, "The corrosion of nickel-aluminium bronze in seawater," Corros. Sci., vol. 47, no. 12, pp. 3336-3367, 2005.

[26] D. Zhang, R. Chen, W. Zhang, Z. Luo, and Y. Li, "Effect of microstructure on the mechanical and corrosion behaviors of a hot-extruded nickel aluminum bronze," vol. 23, no. 2, pp. 113-120, 2010.

[27] R. C. Barik, J. A. Wharton, R. J. K. Wood, K. S. Tan, K. R. Stokes, and M. Planck, "Erosion and Erosion-Corrosion Performance of Cast and Thermally Sprayed Nickel-Aluminium Bronze," 2011. . 
[28] E. A. Culpan and G. Rose, "Corrosion Behaviour of Cast Nickel Aluminium Bronze in Sea Water," Br. Corros. J., vol. 14, no. 3, pp. 160-166, Jan. 1979.

[29] A. V. Takaloo, M. R. Daroonparvar, M. M. Atabaki, and K. Mokhtar, "Corrosion Behavior of Heat Treated Nickel-Aluminum Bronze Alloy in Artificial Seawater," Mater. Sci. Appl., vol. 2, no. 11, pp. 1542-1555, 2011.

[30] J. A. Wharton and K. R. Stokes, "The influence of nickel-aluminium bronze microstructure and crevice solution on the initiation of crevice corrosion," Electrochim. Acta, vol. 53, no. 5, pp. 2463-2473, 2008.

[31] Z. Han and H. Zhao, "Effect of b martensite transformation on dealuminification beha v ior of Cu Á 9Al Á 2Mn alloy in a marine en v ironment," vol. 345, pp. 8-13, 2003.

[32] Z. Han, Y. F. He, and H. C. Lin, "Dealloying characterizations of Cu-Al alloy in marine environment,” J. Mater. Sci., vol. 9, pp. 393-395, 2000.

[33] S. Fonlupt, B. Bayle, D. Delafosse, and J.-L. Heuze, "Role of second phases in the stress corrosion cracking of a nickel - aluminium bronze in saline water," Corros. Sci., vol. 47, pp. 2792-2806, 2005.

[34] A. Schüssler and H. E. Exner, "The corrosion of nickel-aluminium bronzes in seawater-I. Protective layer formation and the passivation mechanism," Corros. Sci., vol. 34, no. 11, pp. 1793-1802, 1993.

[35] B. G. Ateya, E. A. Ashour, and S. M. Sayed, "Corrosion of $\alpha$-Al Bronze in Saline Water,” J. Electrochem. Soc. , vol. 141, no. 1, pp. 71-78, Jan. 1994.

[36] P. Süry and H. R. Oswald, "On the corrosion behaviour of individual phases present in aluminium bronzes," Corros. Sci., vol. 12, no. 1, pp. 77-90, 1972.

[37] F. King, C. D. Litke, M. J. Quinn, and D. M. Leneveu, “Corrosion potential of copper in chloride solutions as a function of oxygen concentration and mass-transfer coefficient," Corros. Sci., vol. 37, no. 5, pp. 833-851, 1995.

[38] "ASTM G32 - 16 Standard Test Method for Cavitation Erosion Using Vibratory Apparatus," ASTM international, 2011. [Online]. Available: http://www.astm.org/cgi-bin/resolver.cgi?G32-16. [Accessed: 13-Feb2013].

[39] N. P. Suh, "The delamination theory of wear," Wear, vol. 25, no. 1, pp. 111124, Jul. 1973.

[40] C. T. Kwok, F. T. Cheng, and H. C. Man, "Synergistic effect of cavitation erosion and corrosion of various engineering alloys in $3.5 \% \mathrm{NaCl}$ solution," Mater. Sci. Eng. A, vol. 290, no. 1-2, pp. 145-154, Oct. 2000.

[41] R. C. Barik, J. A. Wharton, R. J. K. Wood, and K. R. Stokes, "Electromechanical interactions during erosion - corrosion,” Wear, vol. 267, pp. 1900-1908, 2009. 